\title{
A Substituição da Contribuição Patronal para o Faturamento: Efeitos Macroeconômicos, sobre a Progressividade e Distribuição de Renda no Brasil
}

\section{Wilton Bernardino da Silva*, Nelson Leitão Paes ${ }^{\dagger}$, Raydonal Ospina ${ }^{\ddagger}$}

\author{
Conteúdo: 1. Introdução; 2. Modelo Macroeconômico; 3. Calibragem; 4. Reformas \\ Analisadas; 5. Resultados Macroeconômicos para os Agregados e Setores da \\ Economia; 6. Resultados Macroeconômicos para as Famílias; 7. Conclusão. \\ Palavras-chave: Modelos neoclássicos, Reformas tributárias, Desoneração da folha de \\ pagamentos. \\ Códigos JEL: C61, C68, E62.
}

Na esfera Nacional, as Medidas Provisórias 563/2012, 582/2012, 601/2012 e 612/2013 propõem a substituição da alíquota previdenciária patronal do INSS por uma alíquota tributária de $1 \%$ ou $2 \%$ sobre o faturamento, esta alteração sendo feita em setores econômicos intensivos em trabalho. O presente estudo avalia impactos econômicos dessas mudanças sobre os agregados, setores e famílias na economia brasileira. Os resultados sugerem que os efeitos da substituição se devem exclusivamente à redução da carga tributária embutida na proposta, mas sem impacto relevante na redução das distorções do sistema tributário brasileiro.

In Brazil, the Provisional Measures 563/2012, 582/2012, 601/2012 and $612 / 2013$ propose the replacement of the INSS payroll tax by a tax rate of $1 \%$ or $2 \%$ on revenue of the labor-intensive economic sectors. In this paper we evaluate economic impacts of these tax changes on aggregates, sectors and households of the Brazilian economy. The results suggest that the effects of this substitution are given exclusively by the reduction of the embedded

\footnotetext{
*Departamento de Economia, Universidade Federal de Pernambuco, Cidade Universitária, Recife/PE, 50740-540, Brasil. E-mail: wiltonrecc@gmail.com

${ }^{\dagger}$ Departamento de Economia, Universidade Federal de Pernambuco, Cidade Universitária, Recife/PE, 50740-540, Brasil. E-mail: nlpaes@gmail.com

${ }_{\ddagger}^{\ddagger}$ Departamento de Estatística, Universidade Federal de Pernambuco, Cidade Universitária, Recife/PE, 50740-540, Brasil. E-mail: raydonal@de.ufpe.br
} 
tax burden in proposal, but without relevant impact on reduction of the distortions in Brazilian tax system.

\section{INTRODUÇÃO}

Lançado pelo Governo Federal em 2011, o plano Brasil Maior elenca um conjunto de ações econômicas com propósitos alinhados ao crescimento da produtividade, competitividade e sustentabilidade do país. Nesse sentido, uma medida recentemente implementada foi a desoneração da folha de pagamentos. Esse tema foi inicialmente discutido por meio da Lei $\mathrm{n}-12.546$ de 2011 e ampliado com a aprovação das Medidas Provisórias 563/2012, 582/2012, 601/2012 e 612/2013. A desoneração da folha de pagamentos substitui a alíquota previdenciária patronal incidente sobre a folha de salários por uma alíquota inferior incidindo sobre o faturamento, esta modificação devendo ser feita em setores da economia considerados intensivos em trabalho. Com a desoneração patronal, fica estabelecida uma alíquota de $1 \%$ sobre o faturamento para setores em grande parte atrelados à indústria e de $2 \%$ sobre o faturamento para os setores em sua maioria associados aos serviços. Além disso, o programa prevê elevação em um ponto percentual na Contribuição para o Financiamento da Previdência Social (COFINS) em produtos importados desonerados.

O presente estudo utiliza um modelo neoclássico em uma análise de efeitos macroeconômicos para um cenário de mudança fiscal. Em particular, objetiva-se avaliar efeitos de três reformas tributárias, as quais propõem a substituição da alíquota previdenciária patronal dos salários para o faturamento de firmas intensivas em mão de obra (firmas intensivas). Na primeira reforma (reforma 1), utilizase uma alíquota de $1 \%$ sobre o faturamento das firmas intensivas, zerando a alíquota previdenciária patronal para as firmas desse setor, a segunda reforma (reforma 2), utiliza uma alíquota de $2 \%$ sobre o faturamento das firmas intensivas em trabalho tornando nula a alíquota previdenciária patronal para as firmas intensivas. No terceiro cenário (reforma 3), busca-se avaliar os impactos da desoneração patronal em uma reforma neutra relativamente à receita de impostos do governo. Em termos gerais, o modelo considera sete grupos familiares, distribuídos por faixa de renda conforme a Pesquisa de Orçamento Familiar (POF) do IBGE divulgada para o ano de 2008, duas firmas representando a produção de bens intermediários, uma do setor intensivo em mão de obra (setor intensivo) e outra do setor não intensivo em trabalho (setor não intensivo) e uma firma produtora do único bem final da economia.

Como resultado geral do estudo, os efeitos positivos acontecem apenas quando o governo não interfere na arrecadação, i.e., quando a política não é neutra em relação à receita do governo. No cenário em que a receita governamental é mantida constante, os efeitos das reformas são extremamente pequenos, corroborando a tese que, ao se substituir a alíquota patronal para o faturamento aos níveis de $1 \%$ ou $2 \%$, os grandes efeitos se dão em virtude da redução da carga tributária, mas sem impacto importante na diminuição das distorções do sistema tributário brasileiro.

No que tange às contribuições à literatura, o trabalho traz uma visão macro-econômica direcionada na separação das firmas em intensivas e não intensivas em trabalho e com os grupos familiares divididos por faixa de renda conforme dados da Pesquisa de Orçamento Familiar divulgada pelo IBGE em 2008. Nesse sentido, tem-se uma agregação de conhecimento aos estudos nacionais, os quais são bastante elucidativos em análises de impactos econômicos sobre modificações tributárias tendo como ênfase estudos sobre a produção agregada ou sobre firmas formais e informais. Além disso, a metodologia visa na captura de efeitos das mudanças tributárias sobre os grupos familiares, analisando os desagregados da economia.

No âmbito da literatura Nacional, alguns estudos estão alinhados com o tema da desoneração. Em um estudo que desconsidera a heterogeneidade das famílias e das firmas, Cavalcanti (2008) analisa impactos alocativos e de bem-estar associados à alterações tributárias que propõem a substituição de impostos sobre a folha de salários por outro que incide sobre o faturamento das firmas. Bitencourt e Teixeira (2009) analisam efeitos de reduções nos encargos sociais sobre diversos indicadores macro- 
econômicos da economia brasileira. Em uma abordagem neoclássica, Paes (2011) analisa aspectos de uma reforma que propõe a unificação de alguns tributos federais do consumo com a criação de um imposto federal sobre o valor agregado (IVA-F), redução de impostos sobre a folha de pagamentos e bens essenciais, além da desoneração de investimentos. No estudo de Paes (2012) estimam-se os efeitos da mudança da incidência da contribuição previdenciária patronal em alguns setores da economia brasileira considerando uma elevação de $20 \%$ nas alíquotas COFINS afim de manter a neutralidade da arredação.

De uma forma geral, vários trabalhos nessa área voltam-se a analisar efeitos econômicos associados à mudanças tributárias. Uma referência inicial sobre o tema é o trabalho de Fullerton (1982), o qual avalia diversas reformas tributárias na economia americana. Auerbach e Kotlikoff (1987) analisaram efeitos de políticas com impostos sobre a renda, tributos pagos sobre os salários e sobre o consumo na economia americana. No trabalho proposto por Lucas (1990), estudam-se efeitos econômicos de mudanças tributárias que focam em tributação mais extensiva sobre o trabalho, buscando anular a tributação do capital. Cooley e Hansen (1992) analisaram efeitos econômicos de mudanças tributárias que propunham combinar impostos sobre a renda do capital e do trabalho para o financiamento dos gastos do governo americano. Utilizando um modelo OLG (Overlaping Generation Model - Modelo de gerações sobrepostas), Altig et alii (2001) analisaram efeitos macroeconômicos e de bem-estar advindos de diversas alternativas ao imposto sobre a renda nos EUA. No estudo de Prescott (2002), discute-se sobre a questão da carga tributária e suas distorções no trade-off entre consumo e lazer das famílias.

Ferreira e Araújo (1999) avaliam efeitos alocativos e de bem-estar sob cenários de mudanças na política fiscal brasileira entre os anos de 1995 a 1997, propondo a desoneração do setor produtivo e a redução de impostos sobre os salários, de forma a não comprometer a arrecadação do governo. Paes e Bugarin (2006) analisam efeitos econômicos de duas reformas tributárias:

(1) a proposta executiva, que propõe o fim da cumulatividade do PIS e da COFINS, transferência de metade da contribuição patronal sobre a folha de salários para o valor adicionado, unificação do ICMS com sua substituição por um imposto sobre o valor adicionado (IVA) e redução da CPMF; e

(2) a proposta técnica, que propõe a criação de uma contribuição social sobre o valor adicionado (CSVA), criação do IVA que substitui o ICMS, criação do imposto seletivo (IS) que substitui o imposto sobre produtos industrializados (IPI) de cigarros, bebidas, cosméticos, perfumes, joias, bijuterias, telecomunicações, veículos e combustíveis (setores mais tributados pelo ICMS e IPI vigentes na época) e a redução da CPMF.

Além da presente seção, o trabalho é organizado da seguinte forma: na Seção 2, descreve-se o modelo macroeconômico utilizado no estudo; as Seções 3 e 4 descrevem a calibragem do modelo e as reformas analisadas; as Seções 5 e 6 contém a descrição dos resultados e finalmente, na Seção 7 são discutidas as conclusões gerais do trabalho.

\section{MODELO MACROECONÔMICO}

O modelo macroeconômico utilizado nas análises é um modelo neoclássico determinístico, com acumulação de capital e tempo discreto. No modelo, a classificação das famílias segue exatamente a da publicação da POF 2008/2009. A motivação para adotar a divisão das famílias como na POF é que esta dispõe de informações detalhadas sobre despesas e rendimentos de cada grupo familiar de forma desagregada, o que será muito útil na calibragem do modelo. A classificação das famílias, disposta na Tabela 1, permite que todos os grupos constituam poupança, inclusive os de baixo rendimento.

Para este modelo, é suposto que os níveis de consumo e lazer das famílias são escolhidos de forma a maximizar seus fluxos descontados de utilidade restritos aos respectivos limites de orçamento. No lado da produção, há duas firmas intermediárias competitivas, uma representativa do setor intensivo em 
Tabela 1: Discriminação das famílias por classes de renda per capita conforme POF (2008-2009). Valores monetários descritos em reais

\begin{tabular}{c|ccccccc}
\hline \hline Família & 1 & 2 & 3 & 4 & 5 & 6 & 7 \\
\hline Faixa & & mais de & mais de & mais de & mais de & mais de & mais de \\
de & até & 830,00 & $1.245,00$ & $2.490,00$ & $4.150,00$ & $6.225,00$ & $10.375,00$ \\
Renda & 830,00 & $\mathrm{a}$ & $\mathrm{a}$ & $\mathrm{a}$ & $\mathrm{a}$ & $\mathrm{a}$ & \\
& & $1.245,00$ & $2.490,00$ & $4.150,00$ & $6.225,00$ & $10.375,00$ & \\
\hline \hline
\end{tabular}

Fonte: IBGE, 2009.

mão de obra (firma intensiva) e outra representando o setor intensivo em capital (firma não intensiva), e uma firma competitiva produtora do único bem final da economia. O governo arrecada os impostos e utiliza-se desses recursos para ofertar bens públicos e transferir renda para as famílias. A transferência de renda do governo para as famílias é feita por meio de aposentadorias, pensões e programas sociais, dentre outros recursos.

\subsection{Famílias}

O problema das famílias resume-se às escolhas ótimas de consumo, horas de trabalho, lazer e estoques de capital. Com esse propósito, a preços e impostos conhecidos, os grupos familiares maximizam suas utilidades logarítmicas sujeitas às restrições de orçamento. O problema das famílias é dado pela seguinte maximização:

$$
\begin{aligned}
& \max _{c_{i t}, l_{i t}}\left\{\sum_{t \geq 0} \beta^{t}\left[\log \left(c_{i t}\right)+\alpha_{i} \log \left(l_{i t}\right)\right]\right\}, i=1, \ldots, 7, \\
& \text { sujeito a } \\
& P_{t}\left[\left(1+\tau_{c t}\right) c_{i t}+k_{i t+1}-(1-\delta) k_{i t}\right]=\left(1-\tau_{h t}^{i}\right) \xi_{i} w_{t} h_{i t}+\left(1-\tau_{k t}\right) r_{t} k_{i t}+P_{t} T_{i}, \\
& h_{i t}+l_{i t}=1,
\end{aligned}
$$

sendo $\beta$ o fator de desconto intertemporal, $\delta$ o fator de depreciação, $P_{t}$ o preço do bem final, $\alpha_{i}$ o peso relativo do lazer na utilidade e $\xi_{i}$ a produtividade da $i$-ésima família. As quantidades $c_{i t}, l_{i t}, h_{i t}$ e $k_{i t}$ representam o consumo, as horas de lazer, horas de trabalho e o estoque de capital da família $i$ no instante de tempo $t ; r_{t}$ e $w_{t}$ são os preços de aluguel do capital e o salário pagos pelas firmas intermediárias às famílias; $T_{i}$ denota a transferência do governo para a família $i$ no período anterior às reformas. As alíquotas sobre o consumo, renda do trabalho e ganhos de capital são representadas por $\tau_{c t}, \tau_{h t}^{i}$ e $\tau_{k t}$, respectivamente. Os valores de $\tau_{c t}, \tau_{h t}^{i}, i=1 \ldots, 7$, e $\tau_{k t}$ são calibrados para o ano de 2009 e mantidos fixos em todos os períodos seguintes.

As equações de consumo e horas de trabalho da $i$-ésima família são descritas por

$$
\begin{aligned}
& h_{i t}=1-\frac{\alpha_{i}\left(1+\tau_{c t}^{i}\right) P_{t} c_{i t}}{\left(1-\tau_{h t}^{i}\right) \xi_{i} w_{t}}, \\
& c_{i t+1}=\beta \frac{\left(1+\tau_{c t}^{i}\right)}{\left(1+\tau_{c t+1}^{i}\right)}\left[\left(1-\tau_{k t+1}^{i}\right)\left(r_{t+1} / P_{t+1}\right)+(1-\delta)\right] c_{i t} .
\end{aligned}
$$

A equação (4) descreve o trade-off entre consumo e trabalho, enquanto que a equação (5) descreve o trade-off entre consumo futuro e presente para as famílias. 


\subsection{Firmas intermediárias}

A produção de bens é dividida em produtos intermediário e final, havendo duas firmas intermediárias e uma firma produtora de bem final, com um ambiente de mercado competitivo. As firmas intermediárias são divididas em dois setores, o setor intensivo em mão de obra (setor $I$ ) e o setor intensivo em capital (setor $\tilde{I}$ ). Nesta abordagem, Firmas intermediárias alugam capital e trabalho das famílias com a finalidade de produzir bens intermediários, utilizando funções de produção do tipo Cobb-Douglas da forma:

$$
Y_{s t}=A_{s}\left(k_{s t}\right)^{\theta_{s}}\left(h_{s t}\right)^{1-\theta_{s}}, s \in\{I, \tilde{I}\},
$$

em que $Y_{s t}, k_{s t}, h_{s t}$ e $\theta_{s}$ representam, respectivamente, o produto, os fatores de capital e trabalho correspondentes ao setor produtivo $s$ no período $t$ e a participação do fator de capital na produção desse setor. A constante $A_{s}$ denota a tecnologia do setor $s$. No modelo, as firmas intermediárias maximizam os lucros,

$$
\pi_{s t}=\left(1-\tau_{f t}^{s}\right) p_{s t} Y_{s t}-\left(1+\tau_{p t}^{s}\right) w_{s t} h_{s t}-r_{s t} k_{s t}, s \in\{I, \tilde{I}\},
$$

onde $\pi_{s t}$ representa o lucro da firma $s$ no período $t$; $h_{s t}$ e $k_{s t}$ denotam as demandas da firma $s$ por trabalho e capital em $t$; $\tau_{f t}^{s}$ e $\tau_{p t}^{s}$ são as alíquotas sobre o faturamento e folha de pagamentos, pagas pela firma $s$ no período $t ; r_{s t}$ e $w_{s t}$ denotam, respectivamente, o preço de aluguel do capital e o salário pagos pela firma $s$ no $t$-ésimo período; $p_{s t}$ denota o preço do bem intermediário produzido pelo setor $s$ em $t$.

A maximização dos lucros das firmas intermediárias implica as seguintes condições de primeira ordem para $s \in\{I, \tilde{I}\}:$

$$
\begin{aligned}
& r_{s t}=p_{s t}\left(1-\tau_{f t}^{s}\right) \theta_{s} A_{s}\left(k_{s t}\right)^{\theta_{s}-1}\left(h_{s t}\right)^{1-\theta_{s}}, \\
& w_{s t}=\frac{p_{s t}\left(1-\tau_{f t}^{s}\right)\left(1-\theta_{s}\right) A_{s}\left(k_{s t}\right)^{\theta_{s}}\left(h_{s t}\right)^{-\theta_{s}}}{\left(1+\tau_{p t}^{s}\right)} .
\end{aligned}
$$

As equações (8) e (9) determinam os salários e retornos do capital pagos pelas firmas intermediárias às famílias. No modelo, a fim de não haver alocação de trabalho em apenas um setor, assume-se que as firmas pagam os mesmos salários $\left(w_{t}=w_{I t}=w_{\tilde{I}}, \forall t\right)$, e remuneram o capital das famílias com a mesma taxa de retorno $\left(r_{t}=r_{I t}=r_{\tilde{I} t}, \forall t\right)$. Cada família escolhe por trabalhar em um ou mais setores, recebendo uma fração $\gamma \in[0,1]$ do salário pago pela firma $I$ e a fração complementar $(1-\gamma)$ paga pela firma $\tilde{I}$. O salário recebido pela família $i$ depende da sua produtividade $\xi_{i}, i=1, \ldots, 7$, a qual é constante no tempo $\left(w_{i t}=\xi_{i} w, \forall t\right)$.

As horas efetivas totais $h_{t}$, o salário médio $w_{t}$, consumo e capital agregados $\left(c_{t}\right.$ e $k_{t}$, respectivamente) são obtidos pelas expressões

$$
h_{t}=\sum_{i=1}^{7} \eta_{i} \xi_{i} h_{i t} ; w_{t}=\sum_{i=1}^{7} \eta_{i} w_{i t} ; c_{t}=\sum_{i=1}^{7} \eta_{i} c_{i t} ; k_{t}=\sum_{i=1}^{7} \eta_{i} k_{i t},
$$

em que $\eta_{i}, i=1, \ldots, 7$, denota a participação da família $i$ na população. Os pesos $\eta_{i}, i=1, \ldots, 7$, foram obtidos da POF (2008-2009) dividindo-se a quantidade de famílias na classe $i$ pelo total de grupos nas sete classes de rendimento.

\subsection{Firma produtora de bem final}

A firma produtora de bem final é competitiva e forma seu produto pela combinação de bens intermediários, utilizando a tecnologia

$$
Y_{t}=\left[Y_{I t}^{1 / \lambda}+Y_{\tilde{I} t}^{1 / \lambda}\right]^{\lambda}
$$


em que $1<\lambda<\infty$ denota o parâmetro de elasticidade de substituição entre os insumos intermediários. Denotando por $\sigma$ a elasticidade de substituição entre os bens intermediários, tem-se que $\sigma=\frac{\lambda}{\lambda-1}$, assim, quando $\lambda \rightarrow 1^{+}$, os bens tendem a ser substitutos perfeitos. Se $\lambda \rightarrow \infty$, os bens tendem a ser complementares perfeitos. No presente estudo, $\lambda=1,85$, que é o referencial de elasticidade utilizado em Paes (2012), sendo também uma estimativa adotada na literatura internacional (ver Christiano et alii, 2005).

A maximização dos lucros $\Pi_{t}=P_{t} Y_{t}-p_{I t} Y_{I t}-p_{\tilde{I} t} Y_{\tilde{I} t}, \forall t$, implica nas seguintes condições de primeira ordem:

$$
\left(\frac{p_{s t}}{P_{t}}\right)^{\frac{\lambda}{1-\lambda}}=\frac{Y_{s t}}{Y}, s \in\{I, \tilde{I}\} .
$$

Pelas equações (11) e (12), o preço do único bem final da economia é dado por:

$$
P_{t}=\left[p_{I t}^{1 /(1-\lambda)}+p_{\tilde{I} t}^{1 /(1-\lambda)}\right]^{1-\lambda}
$$

\subsection{Governo}

O governo possui orçamento equilibrado, utilizando-se da arrecadação em impostos para o financiamento de gastos públicos e transferências, seguindo a restrição

$$
\begin{aligned}
P_{t}\left[G_{t}+T\right] & =\tau_{c t} \sum_{i=1}^{7} \eta_{i} c_{i t}+\tau_{k t} \sum_{i=1}^{7} r_{t} \eta_{i} k_{i t}+\sum_{i=1}^{7} \tau_{h t}^{i} \eta_{i} w_{i t} h_{i t} \\
& +\sum_{s \in\{I, \tilde{I}\}} \tau_{p t}^{s} w_{s t} h_{s t}+\sum_{s \in\{I, \tilde{I}\}} \tau_{f t}^{s} p_{s t} Y_{s t},
\end{aligned}
$$

sendo $G_{t}$ o gasto do governo no período $t \mathrm{e}$

$$
T=\sum_{i=1}^{7} \eta_{i} T_{i}
$$

as transferências lump-sum do governo às famílias no período que antecede as reformas.

\subsection{Equilíbrio}

Nas trajetórias de equilíbrio, as famílias escolhem sequências de consumo $c_{i t}$, horas de trabalho $h_{i t}$ e estoque de capital $k_{i t}(i=1, \ldots, 7)$ que maximizam suas funções de utilidade restritas aos limites de orçamento. As firmas intermediárias escolhem sequências de estoque de capital $\left(k_{s t}, s \in\{I, \tilde{I}\}\right)$ e de horas de trabalho $\left(h_{s t}, s \in\{I, \tilde{I}\}\right)$ que maximizam seus lucros e a firma de bem final combina bens intermediários de forma a maximizar lucros.

O cálculo do equilíbrio do modelo é dado pela solução do sistema não linear formado pelas equações (4), (5), pelas equações (8) e (9) obtidas com as igualdades $r_{I t}=r_{\tilde{I} t}$ e $w_{I t}=w_{\tilde{I} t}$, pelas equações (10), (13), (14) e (15), sendo $t=1, \ldots, \mathbf{T}$, e dados os estoques de capital iniciais $k_{j 0}, j=1, \ldots, 7$, em que $\mathbf{T}=100$ denota o último período da transição.

$\mathrm{Na}$ obtenção das trajetórias das variáveis $\left\{c_{t}, h_{t}, h_{I t}, h_{\tilde{I} t}, k_{t}, k_{I t}, k_{\tilde{I} t}, p_{I t}, p_{\tilde{I} t}\right\}, t=1, \ldots, \mathbf{T}$, utilizou-se como método de solução o algoritmo de otimização não linear proposto por Broyden (1965), o qual é um algoritmo quasi-Newton que busca pelas soluções ao resolver de forma simultânea um único sistema de equações não lineares associadas aos períodos que sucedem a implementação das 
reformas tributárias analisadas. Em outras palavras, para cada reforma, resolve-se o sistema não linear composto pelas equações acima descritas, nas variáveis $\left\{c_{t}, h_{t}, h_{I t}, h_{\tilde{I} t}, k_{t}, k_{I t}, k_{\tilde{I} t}, p_{I t}, p_{\tilde{I} t}, G_{t}\right\}$, para $t=1, \ldots, \mathbf{T}$.

\section{CALIBRAGEM}

O procedimento de calibragem consiste em encontrar valores para os parâmetros e variáveis do modelo que estejam de acordo com os dados reais. Para tanto, assume-se que o sistema formado pelas equações de equilíbrio esteja em um ponto inicial onde a variação no estoque de capital seja nula (o estado estacionário inicial). Aqui, são utilizados os dados das Contas Nacionais do ano 2009 para calcular as variáveis e parâmetros de interesse no primeiro equilíbrio estacionário da economia (assumido de acontecer em 2009). A calibragem também utiliza dados do Censo/2010, da POF (2008/2009), todas as informações sendo extraídas da base de dados do IBGE.

A Tabela 2 resume os setores da economia classificados como intensivos em trabalho e não intensivos em trabalho (intensivos em capital). Com base nas Contas Nacionais do IBGE, a classificação adotada considera como intensivos em capital os setores para os quais o excedente operacional bruto é maior do que a remuneração do trabalho e intensivos em trabalho quando ocorre o inverso.

\subsection{Distribuição das famílias}

A distribuição das famílias é feita utilizando os dados do Censo/2010, dividindo-se os números de famílias presentes em cada grupo pelo número total de famílias na população, obtendo-se assim as participações dos grupos familiares, descritas no modelo por $\eta_{i}, i=1, \ldots, 7$. Os valores calculados são apresentados na Tabela 3.

\subsection{Participações do capital}

A participação do capital na renda do setor intensivo, representada pelo parâmetro $\theta_{I}$, foi obtida dividindo-se o correspondente excedente operacional bruto pela soma das remunerações aos empregados com o excedente operacional bruto do setor intensivo. De forma análoga, o valor da participação do capital na renda do setor não intensivo, $\theta_{\tilde{I}}$, foi obtido dividindo-se o correspondente excedente operacional bruto pela soma das remunerações aos empregados com o excedente operacional bruto do setor não intensivo. Após estes cálculos, os valores calibrados para as participações do capital foram $\theta_{I}=0,2930$ (intensivo) e $\theta_{\tilde{I}}=0,7280$ (não intensivo).

\subsection{Arrecadação e alíquotas tributárias}

A arrecadação tributária advém de impostos sobre a renda do trabalho, encargos previdenciários patronais, impostos sobre a renda do capital e sobre o consumo. No cálculo dos valores de (arrecadação)/PIB foram utilizados dados das Contas Nacionais e da POF do IBGE.

A arrecadação do trabalho foi dividida em duas partes, uma advinda de impostos que são fixados para todos os grupos familiares, sendo consideradas neste grupo as contribuições dos empregados aos institutos oficiais de previdência, o FGTS e o PIS/PASEP, as contribuições previdenciárias do funcionalismo público e impostos sobre a folha de salários. A segunda parte da arrecadação advém de impostos que variam de acordo com os rendimentos das famílias. Nesse grupo de arrecadação são incluídos o imposto de renda pessoa física (IRPF) e o imposto de renda retido na fonte (IRRF).

Com o auxílio dos dados da POF/2008, a parcela da arrecadação do trabalho sobre o PIB referente aos impostos de renda pessoa física e retido na fonte (IRPF e IRRF, respectivamente) foi distribuída entre as famílias de modo que a média ponderada das arrecadações de IRPF e IRRF por família, com pesos iguais aos respectivos $\eta_{i}, i=1, \ldots, 7$, resulte na relação (arrecadação)/PIB calculada pelas Contas 


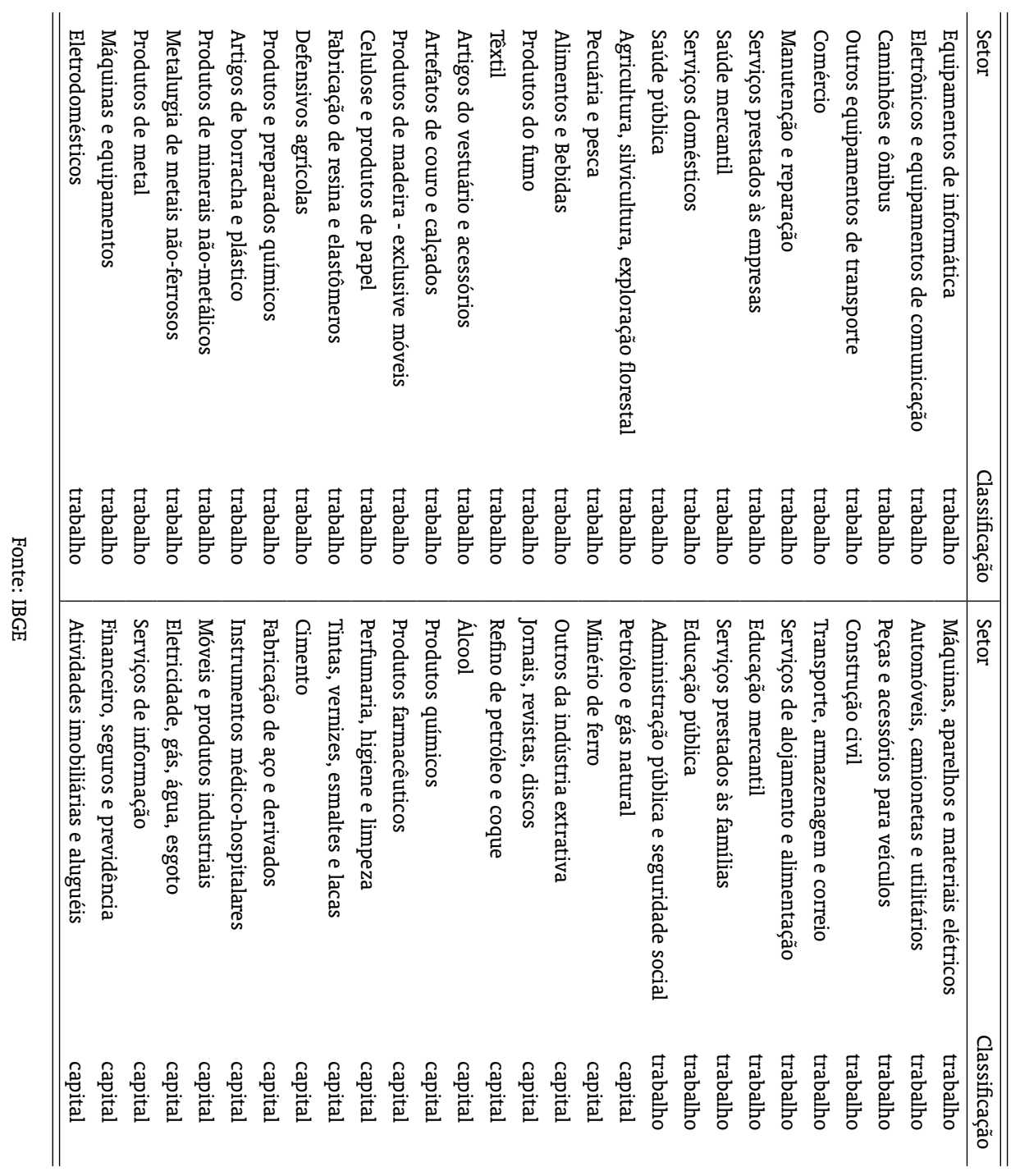

总

莡

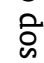

峞

คิ

0
0
0
0
$\vdots$
0
0
0
0
0
0
0
0
0
3
5
0
0
0
0
0
0

罗

今

若

울

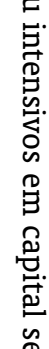

垔

is

กิ

命

杳 
Tabela 3: Distribuição das famílias segundo Censo 2010

\begin{tabular}{ccc}
\hline \hline Família & Número de Famílias & Participação $\left(\eta_{i}\right)$ \\
\hline Família 1 & 12.503 .385 & $21,63 \%$ \\
Família 2 & 10.069 .184 & $17,42 \%$ \\
Família 3 & 16.972 .311 & $29,36 \%$ \\
Família 4 & 8.890 .463 & $15,38 \%$ \\
Família 5 & 4.181 .485 & $7,23 \%$ \\
Família 6 & 2.994 .837 & $5,18 \%$ \\
Família 7 & 2.204 .938 & $3,81 \%$ \\
\hline Total & 57.816 .604 & $100 \%$ \\
\hline \hline
\end{tabular}

Fonte: Censo/IBGE.

Nacionais. A distribuição dos valores é descrita a seguir: (1) Seja $\operatorname{arrtrab} b_{1}$ a arrecadação em impostos de renda da POF advinda da família 1; (2) Dividem-se as arrecadações da POF pela arrecadação da família 1, obtendo-se o vetor de arrecadações relativas à arrecadação dessa família e denotado por $\left[1, \frac{a r r t r a b_{2}}{a r r t r a b_{1}}, \ldots, \frac{a r r t r a b_{7}}{\text { arrtrab }}\right]^{\top}$; (3) Escolhe-se o valor de $v$ que resolve a equação $\sum_{i=1}^{7} \eta_{i}\left(\frac{a r r t r a b_{i}}{a_{r} t r a b_{1}}\right) v=$ $a r r_{2}$, em que $a r r_{2}$ é a razão (arrecadação)/PIB referente à parcela da arrecadação em IRPF e IRRF obtida das Contas Nacionais; (4) As arrecadações em IRPF e IRRF por família são então estabelecidas pelo vetor $\left[v, \frac{a r r t r a b_{2}}{\text { arrtrab }} v, \ldots, \frac{a r r t r a b_{7}}{a r r t r a b_{1}} v\right]^{\top}$, cujas componentes estão dadas como frações do PIB. Essa metodologia permite o cálculo das arrecadações de IRPF e IRRF por família de maneira proporcional às densidades populacionais de cada grupo familiar e relativas ao produto da economia.

Dos dados, foram calculadas as alíquotas tributárias do trabalho por família utilizando a seguinte expressão:

$$
\tau_{h}^{i}=\frac{a r r_{1}}{\frac{w h}{Y}}+\frac{a r r_{2}^{i}}{\frac{\xi_{i} w h_{i}}{Y}}, i=1, \ldots, 7,
$$

onde $a r r_{1}=6.66 \%$ é a (arrecadação)/PIB do trabalho que independe da classe de renda dos grupos familiares, $a r r_{2}^{i}$ denota a (arrecadação)/PIB referente a IRPF e IRRF advinda da família $i(0,25 \%, 0,39 \%$, $0,91 \%, 2,27 \%, 4,93 \%, 10,69 \%$ e $34.16 \%, i=1, \ldots, 7$, respectivamente), $h$ são as horas efetivas de trabalho da economia, $\xi_{i}$ e $h_{i}$ denotam a produtividade e as horas de trabalho da família $i$, respectivamente. As alíquotas tributárias do consumo e capital são obtidas dividindo-se as correspondentes participações das arrecadações no PIB pelas razões (consumo)/PIB e (capital)/PIB, respectivamente. A alíquota previdenciária patronal é obtida dividindo-se a participação da arrecadação previdenciária patronal sobre o PIB pela relação renda/PIB do trabalho.

\subsection{Horas trabalhadas}

O cálculo das horas de trabalho por família é feito com a utilização de dados do Censo/2010, de onde extraem-se as horas médias de trabalho por região brasileira e, considerando esses valores como referenciais de horas trabalhadas pelos indivíduos de uma mesma região, calculam-se as médias de horas trabalhadas em cada faixa de renda. Por fim, dividindo-se os valores encontrados por 168 (valor em horas de trabalho que corresponde a uma jornada média de 7 dias de atividade laboral) obtêm-se as horas médias de trabalho em jornadas semanais. 


\subsection{Consumo desagregado}

Conforme dados das Contas Nacionais referentes ao ano de 2009, a relação (consumo)/PIB foi de $61,02 \%$. Este valor foi considerado como consumo líquido da economia e distribuído entre os sete grupos familiares de maneira proporcional às respectivas participações na população e seguindo os dados referentes ao consumo das famílias obtidos na POF/2008. A metodologia de cálculo do consumo desagregado é análoga à utilizada para a arrecadação em IRRF e IRPF (Subseção 3.3).

\subsection{Salários}

No cálculo dos salários desagregados foram utilizados os dados da POF/2008 referentes aos rendimentos familiares. Para todos os grupos familiares utilizou-se como referência de rendimentos a soma das rendas advindas de transferências de aposentadorias, pensão da previdência privada, pensão alimentícia, mesada e doação, além dos rendimentos advindos do trabalho (empregado), por conta própria e não monetários. Os valores obtidos da POF foram então redistribuídos entre as sete famílias proporcionalmente às respectivas participações na população, seguindo a mesma metodologia utilizada para a arrecadação em IRRF e IRPF (Subseção 3.3).

\subsection{Estoques de capital e produtividades das familias}

Os estoques de capital das famílias são calculados pelas suas restrições orçamentárias, as quais resultam na seguinte relação:

$$
\frac{k_{i}}{Y}=\frac{\left(1-\tau_{h}^{i}\right)\left[\frac{w_{i} h_{i}}{Y}\right]-\left(1+\tau_{c}\right)\left[\frac{c_{i}}{Y}\right]+\frac{T_{i}}{Y}}{\delta-r\left(1-\tau_{k}^{i}\right)}, i=1, \ldots, 7,
$$

considerando $r$ igual a taxa de juros básica da economia brasileira (taxa SELIC), que ao fim de 2009 atingiu o patamar de $r=8,75 \%$ ao ano.

A produtividade do trabalho atribuída à $i$-ésima família é mantida constante em todos os períodos, sendo calculada pela seguinte expressão:

$$
\xi_{i}=\frac{w_{i}}{\sum_{i=1}^{7} \eta_{i} w_{i}}, i=1, \ldots, 7
$$

\subsection{Transferências}

Para calcular as transferências das famílias, primeiramente calcula-se a relação (transferência)/PIB da economia utilizando a equação (14), a qual fornece a relação $\frac{T}{Y}=12,48 \%$. Seguindo a mesma metodologia da Subseção 3.3, esse percentual é então distribuído entre os sete grupos familiares de maneira proporcional às respectivas participações na população e de acordo com os dados da POF/2008 referentes à aposentadoria, pensão do INSS, pensão da previdência pública, programas sociais federais e outras transferências.

\subsection{Depreciação}

Para calibrar o parâmetro de depreciação $\delta$, dadas as razões (investimento)/PIB $\left(\frac{I}{Y}\right)$ e capital/produto $\left(\frac{k}{Y}\right)$, no estado estacionário, são válidas as seguintes relações: $I=k_{t+1}-(1-\delta) k_{t}$ e $k_{t+1}=k_{t}$. Dessa forma, tem-se $\delta=\frac{I}{Y} / \frac{k}{Y}$. 


\subsection{Demais parâmetros e variáveis do modelo}

Os demais parâmetros e variáveis do modelo são obtidos utilizando-se as equações de equilíbrio descritas na Subseção 2.5, condicionadas ao primeiro estado estacionário da economia, em que $k_{t+1}=$ $k_{t}$. As Tabelas 4 e 5 apresentam os resultados da calibragem para os agregados, setores da economia e grupos familiares considerados pelo modelo.

Tabela 4: Resumo dos Parâmetros e Variáveis dos Agregados da Economia em 2009

\begin{tabular}{cll}
\hline \hline Parâmetro/Variável & Característica & Valor \\
\hline$\delta$ & depreciação & $3,69 \%$ \\
$\beta$ & fator de desconto intertemporal & 0,9634 \\
$\theta_{I}$ & participação do capital no produto intensivo & 0,2930 \\
$\theta_{\tilde{I}}$ & participação do capital no produto não intensivo & 0,7280 \\
$\tau_{k}$ & alíquota sobre o capital & $14,41 \%$ \\
$\tau_{c}$ & alíquota sobre o consumo & $23,13 \%$ \\
$\tau_{p}$ & alíquota previdenciária patronal & $7,12 \%$ \\
$G$ & gastos do Governo/PIB & $21,17 \%$ \\
$C$ & consumo/PIB & $61,02 \%$ \\
$T$ & transferências/PIB & $12,48 \%$ \\
$G+T$ & arrecadação/PIB & $33,64 \%$ \\
$k$ & estoque de capital agregado/PIB & 4,8265 \\
$k_{I}$ & capital intensivo & 2,3534 \\
$k_{\tilde{I}}$ & capital não intensivo & 2,4731 \\
$h$ & horas efetivas de trabalho & 0,2318 \\
$h_{I}$ & horas intensivas & 0,1993 \\
$h_{\tilde{I}}$ & horas não intensivas & 0,0324 \\
$r$ & taxa de juros & $8,75 \%$ \\
$w / Y$ & salário médio & 2,3267 \\
$p_{I}$ & preço do bem intensivo & 1,3496 \\
$p_{\tilde{I}}$ & preço do bem não intensivo & 2,8045 \\
\hline \hline & &
\end{tabular}

Fonte: Elaboração própria.

\section{REFORMAS ANALISADAS}

No presente estudo três reformas são analisadas dentro do contexto de propor a substituição da contribuição patronal, antes com base de cálculo sobre o trabalho, para o faturamento das firmas intensivas em mão de obra. A primeira reforma (reforma 1) consiste em alterar as alíquotas $\tau_{f t}^{I}$ para $1 \%$ e tornar nulas as alíquotas $\tau_{p t}^{I}$, para $t=1, \ldots$, T. Na segunda reforma (reforma 2), as alíquotas $\tau_{f t}^{I}$ são modificadas para $2 \%$ e as alíquotas $\tau_{p t}^{I}$, como na reforma 1 , são iguais a zero, para $t=1, \ldots, \mathbf{T}$.

A terceira reforma (reforma 3) propõe uma análise sob a condição de neutralidade de arrecadação. Para tanto, a alíquota tributária incidente sobre o faturamento intensivo é escolhida de modo que, no estado estacionário inicial, a arrecadação do trabalho se iguale à arrecadação sobre o faturamento das firmas intensivas. $O$ objetivo dessa simulação é examinar se eventuais resultados positivos das reformas 1 e 2 decorrem apenas da redução da carga tributária e das distorções a ela associadas, ou se há ganhos de eficiência na mudança da base tributária da folha de pagamentos para o faturamento. 
Tabela 5: Resumo dos parâmetros e variáveis desagregadas da economia calibrados para 2009

\begin{tabular}{|c|c|c|c|c|c|c|c|c|}
\hline \multirow[t]{2}{*}{ Parâmetro } & \multirow[t]{2}{*}{ Descrição } & \multicolumn{7}{|c|}{ Família } \\
\hline & & 1 & 2 & 3 & 4 & 5 & 6 & 7 \\
\hline$\eta_{i}$ & $\begin{array}{l}\text { participação na } \\
\text { população }\end{array}$ & $21,63 \%$ & $17,42 \%$ & $29,36 \%$ & $15,38 \%$ & $7,23 \%$ & $5,18 \%$ & $3,81 \%$ \\
\hline$w_{i} / Y$ & salário/PIB & 0,4907 & 0,9123 & 1,6370 & 2,8827 & 4,3949 & 6,5201 & 12,6456 \\
\hline$c_{i} / Y$ & consumo/PIB & 0,1298 & 0,2460 & 0,4197 & 0,7439 & 1,1476 & 1,7284 & 3,3862 \\
\hline$T_{i} / Y$ & transferência/PIB & 0,0358 & 0,0684 & 0,0906 & 0,1373 & 0,1990 & 0,3094 & 0,7075 \\
\hline$\alpha_{i}$ & peso do lazer & 2,0210 & 1,9842 & 2,0741 & 2,0365 & 1,9784 & 1,8964 & 1,7706 \\
\hline$k_{i} / Y$ & capital/PIB & 0,7314 & 1,3901 & 2,6977 & 5,6676 & 9,7484 & 15,8131 & 32,4794 \\
\hline$\tau_{h}^{i}$ & $\begin{array}{l}\text { alíquota do } \\
\text { trabalho }\end{array}$ & $14,57 \%$ & $14,20 \%$ & $14,75 \%$ & $15,75 \%$ & $17,19 \%$ & $19,42 \%$ & $24,00 \%$ \\
\hline$\xi_{i}$ & $\begin{array}{l}\text { produtividade do } \\
\text { trabalho }\end{array}$ & 0,2109 & 0,3921 & 0,7036 & 1,2390 & 1,8889 & 2,8024 & 5,4351 \\
\hline
\end{tabular}

Fonte: Elaboração própria.

\section{RESULTADOS MACROECONÔMICOS PARA OS AGREGADOS E SETORES DA ECONOMIA}

As análises são feitas dentro de um período de 100 anos após cada reforma, onde procura-se observar o comportamento das variáveis relativamente às condições do equilíbrio inicial. Em todas as reformas, a fim de que o gasto do governo não afete os rendimentos das famílias, as transferências do governo aos grupos familiares são consideradas constantes e nos níveis calibrados para o primeiro estado estacionário da economia. Na reforma 3, considerando toda a fase de transição, a média das diferenças das arrecadações à arrecadação do primeiro estado estacionário é cerca de $0,016 \%$ em valor presente, o que torna a simulação neutra relativamente à arrecadação tributária.

A Figura 1 apresenta as trajetórias associadas às variáveis agregadas ao se considerar a reforma 1 . Pelos resultados, observam-se aumentos gradativos no estoque de capital, trabalho, consumo e produto. Consumo e trabalho apresentam as maiores taxas de crescimento durante a transição, fator resultante do benefício da desoneração do trabalho para as firmas intensivas. Nesse sentido, o aumento das horas de trabalho contribui para o crescimento da renda das famílias, que aumentam os níveis de consumo. $\mathrm{O}$ crescimento do produto é consequência do aumento no emprego e estoque de capital. No curto e longo prazos, o comportamento do capital justifica a trajetória do investimento, que cresce de forma levemente superior nos primeiros períodos da transição.

A queda na arrecadação é fator predominante, principalmente nos primeiros períodos seguintes à reforma, onde a perda chega próximo de $4 \%$ em relação ao cenário inicial. Essa retração é apenas atenuada nos períodos seguintes. Como fator resultante, há impacto nas variações dos gastos do governo: no primeiro período após a reforma, os gastos apresentam quedas de aproximadamente $6,3 \%$; ao longo da trajetória, observa-se uma redução gradativa nas quedas dos gastos, que se estabilizam aproximadamente $6,1 \%$ abaixo do referencial do primeiro equilíbrio estacionário da economia.

A Figura 2 contém os gráficos associados à reforma 2. Aqui, o trabalho, consumo e produto apresentam taxas de crescimento (no curto, médio e longo prazos) inferiores às alcançadas com a reforma 1 , o estoque de capital e o investimento sofrem leves quedas a longo prazo. Esse resultado decorre 
Figura 1: Resultados para os agregados com trajetórias de transição após reforma 1. No eixo vertical têm-se as variações percentuais relativas aos valores calibrados no primeiro estado estacionário. 0 eixo horizontal é o tempo em anos após a reforma
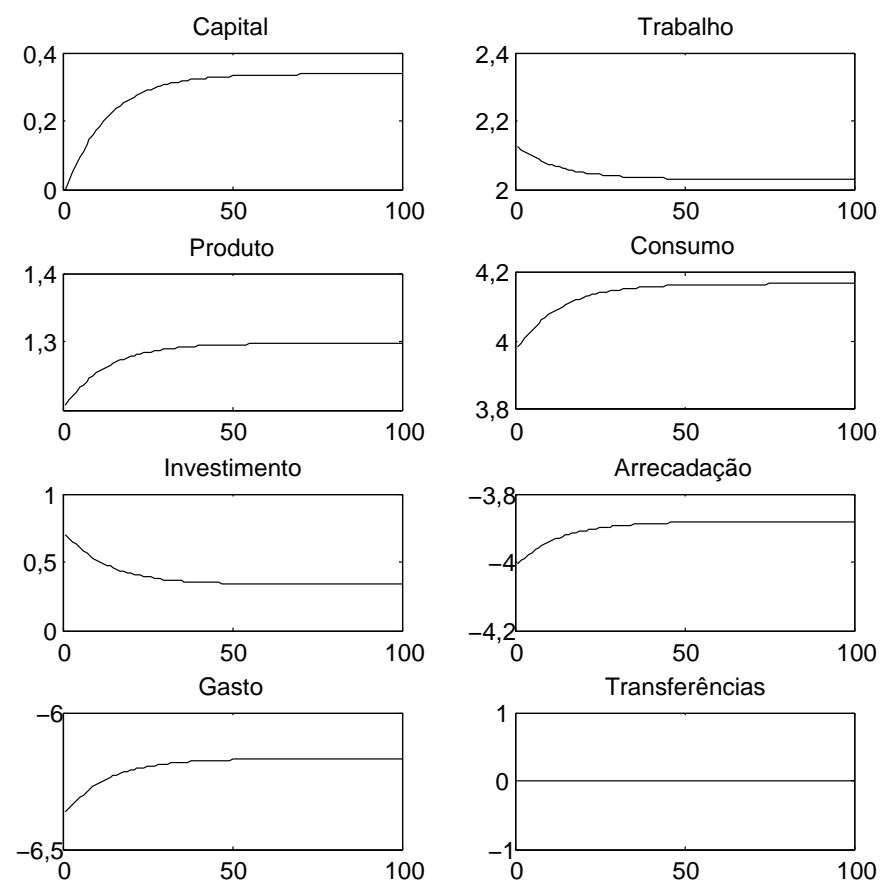

do aumento no custo tributário existente da primeira reforma para a segunda. Fato é que, com um imposto mais elevado incidindo sobre o faturamento das firmas intensivas, o estoque de capital desse setor passa a ser mais onerado, sofrendo leve retração, impactando diretamente no estoque de capital agregado.

A queda no estoque de capital agregado acarreta perdas no investimento, que retrai aproximadamente $1,25 \%$ no primeiro período, estabilizando-se em um valor próximo ao do estado estacionário inicial (queda de aproximadamente $0,6 \%$ ). Com a segunda reforma, o emprego aumenta cerca de $1,56 \%$ no primeiro período, estabilizando-se com um aumento aproximado de $1,72 \%$.

O crescimento do consumo é maior no primeiro período após a reforma, sofrendo reduções gradativas até atingir o valor de longo prazo cerca de $3 \%$ superior ao do primeiro estado estacionário. Nesse cenário de reforma, trabalho e consumo contribuem mais para o crescimento do produto, que aumenta levemente no curto prazo (cerca de $0,88 \%$ ), permanecendo estável no longo prazo (crescimento aproximado de $0,73 \%$ ). No que tange aos gastos do governo, dado que a queda na arrecadação é relativamente menor na segunda reforma, essa variável sofre reduções também inferiores tanto a curto como a longo prazo. Nesse sentido, a perda de arrecadação, mesmo inferior à da reforma 1, apresenta retrações consideráveis (aproximadamente $-2,7 \%$ no período inicial e $-2,92 \%$ a longo prazo).

Os gráficos referentes à terceira reforma são mostrados na Figura 3. Como é possível observar, o aumento da alíquota sobre o faturamento onera ainda mais o fator capital, que apresenta perda superior a $2 \%$ a longo prazo. o emprego apresenta-se estável no curto prazo e tem leve crescimento 
Figura 2: Resultados para os agregados com trajetórias de transição após reforma 2. No eixo vertical têm-se as variações percentuais relativas aos valores calibrados no primeiro estado estacionário. 0 eixo horizontal é o tempo em anos após a reforma
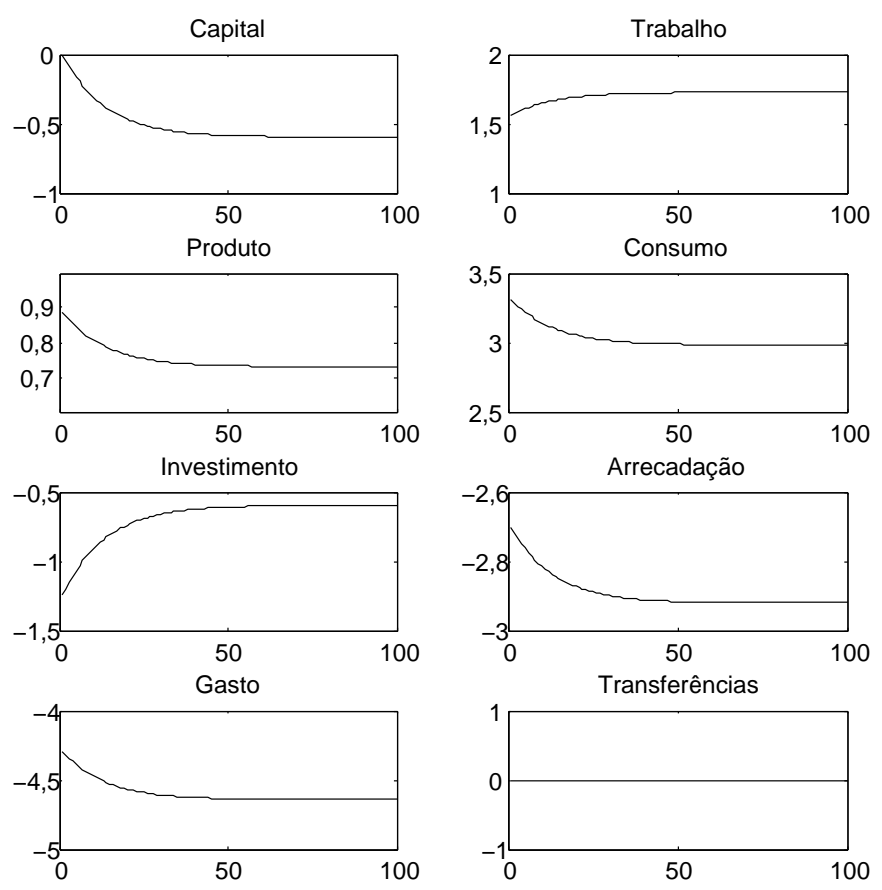

$(+0,88 \%)$ no segundo estado estacionário. O baixo crescimento apresentado pelo trabalho favorece a elevação do consumo no curto prazo, que cresce cerca de $1,5 \%$, no entanto, a trajetória de longo prazo do emprego contribui para o retorno do consumo a um nível próximo do primeiro equilíbrio estacionário (crescimento aproximado de $0,88 \%$ a longo prazo). Como consequência, as trajetórias do emprego e do consumo são insuficientes para garantir o crescimento do produto, que sofre leve retração a longo prazo (aproximadamente $-0,83 \%$ ).

A trajetória do capital justifica o percurso do investimento, que retrai fortemente no primeiro período (aproximadamente $-6,5 \%$ ), atenuando as perdas a longo prazo (aproximadamente $-3,11 \%$ ). 0 gasto do governo aumenta levemente no primeiro período da transição, permanecendo em nível próximo ao do primeiro estado estacionário a longo prazo (leve queda de $0,46 \%$ ).

o comportamento setorial pode ser visto nas Figuras 4, 5 e 6 (reformas 1 a 3, respectivamente). Com a primeira reforma, dado o benefício tributário destinado às firmas intensivas, estas aumentam a demanda por trabalho e estoque de capital, o que implica aumento do produto intensivo. 0 trabalho intensivo cresce inicialmente cerca de $3.25 \%$ e estabiliza-se com um crescimento aproximado de $3,13 \%$. O estoque de capital intensivo aumenta pouco nos períodos iniciais, apresentando uma trajetória ascendente até atingir um patamar no longo prazo de cerca de $0,9 \%$ acima do calibrado para o primeiro equilíbrio estacionário da economia.

As trajetórias do capital e do trabalho intensivos indicam um comportamento ascendente do produto intensivo, que aumenta cerca de $2.49 \%$ logo após a reforma e se estabiliza no valor aproximado de $2,48 \%$. 
Figura 3: Resultados para os agregados com trajetórias de transição após reforma 3. No eixo vertical têm-se as variações percentuais relativas aos valores calibrados no primeiro estado estacionário. 0 eixo horizontal é o tempo em anos após a reforma
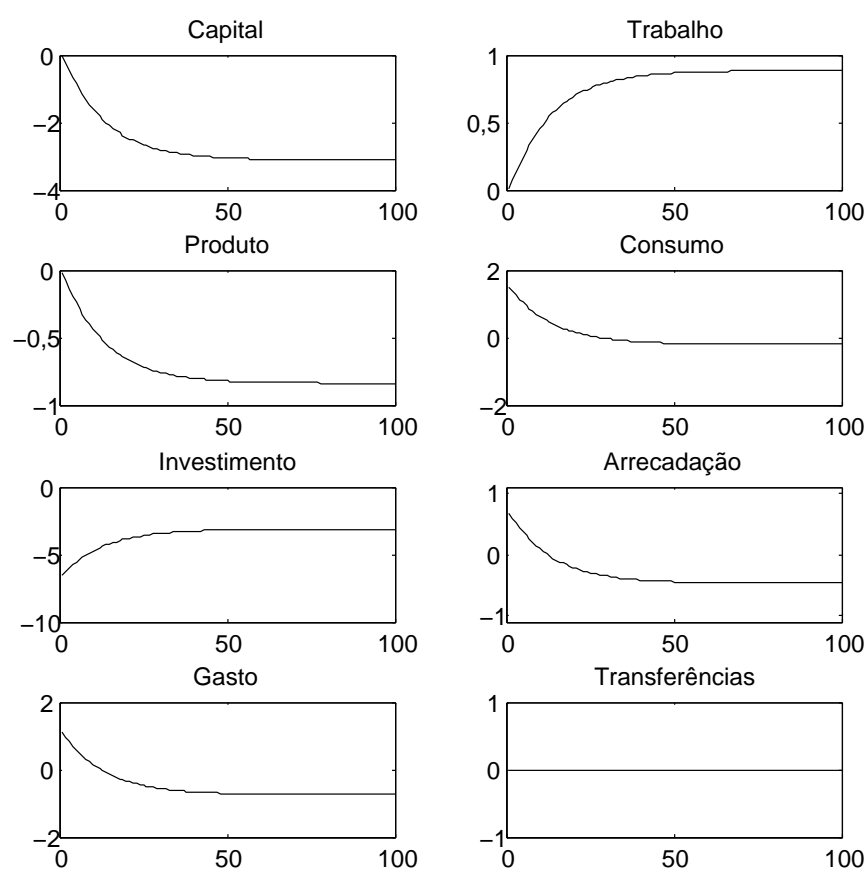

Observando o lado das firmas não intensivas, trabalho, capital e produto retraem no curto prazo, essas quedas sendo atenuadas durante a transição, com o capital e produto do setor estabilizandose próximos dos valores anteriores à reforma, mas com o trabalho retraindo aproximadamente $4,8 \%$ no longo prazo. Esse impacto negativo sobre o trabalho não intensivo reflete o efeito substituição prevalecente entre as alocações de trabalho das famílias, que aumentam a oferta de trabalho para o setor intensivo.

A segunda reforma parece não beneficiar tanto o setor intensivo como na primeira reforma, reduzindo o estoque de capital e aumentando menos o trabalho e produto desse setor (ver Figura 5). 0 trabalho intensivo cresce cerca de $2,4 \%$ no período inicial, apresentando comportamento ascendente até atingir um limiar de crescimento em cerca de $2,62 \%$ a longo prazo. Com a segunda reforma, o produto intensivo cresce cerca de $1,57 \%$ no primeiro período após a mudança, aumentando gradativamente a taxa de crescimento até se estabilizar aproximadamente 1,59\% acima do patamar calibrado no primeiro estado estacionário, valor inferior ao apresentado com a primeira reforma.

Esse menor crescimento do produto intensivo é reflexo da leve retração no estoque de capital intensivo, que recua cerca de $0,39 \%$ no primeiro período e se estabiliza aproximadamente de $0,82 \%$ abaixo do valor calibrado para 2009.

Pelo lado das firmas não intensivas, observam-se quedas no trabalho e produto, mas diferentemente da reforma 1, o estoque de capital cresce levemente no curto prazo e sofre pequena retração no segundo estado estacionário da economia, estabilizando-se próximo ao nível do primeiro equilíbrio da economia (queda de aproximadamente $0,37 \%$ ). Relativamente à primeira reforma, o setor não intensivo apresenta 
Figura 4: Resultados setoriais com trajetórias de transição após reforma 1. No eixo vertical, têm-se as variações percentuais relativas aos valores calibrados no primeiro estado estacionário. $O$ eixo horizontal é o tempo em anos após a reforma
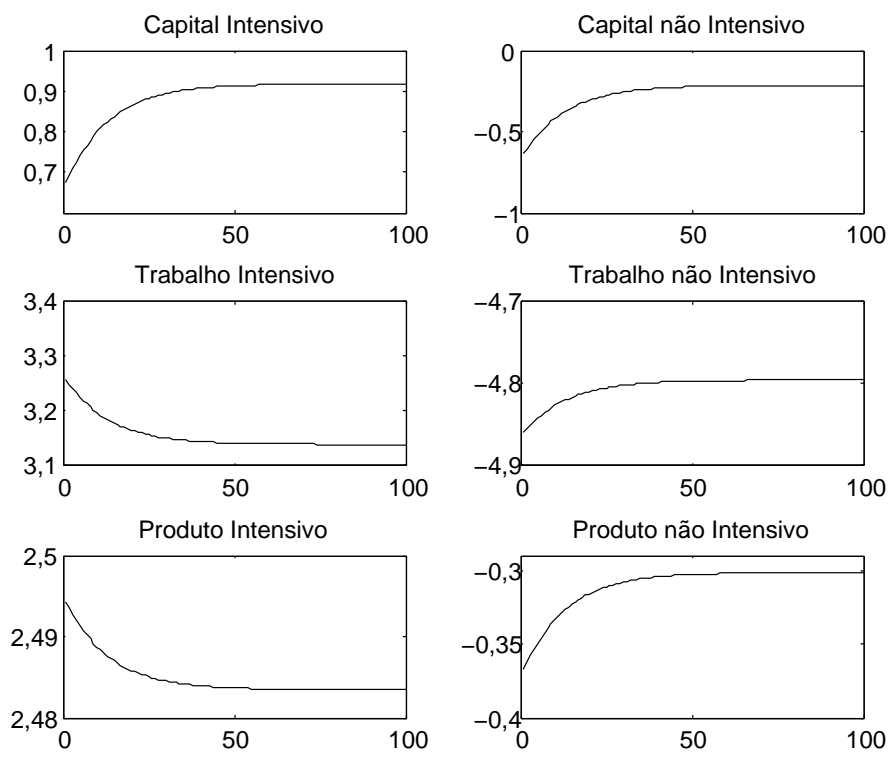

menor retração no emprego e ainda impacta negativamente no produto desse setor, que sofre leve retração no curto e longo prazo.

Os resultados da terceira reforma com enfoque setorial são mostrados na Figura 6. Como é possível observar, a elevação da alíquota incidente sobre o faturamento das firmas intensivas onera ainda mais o fator capital desse setor, que retrai aproximadamente $3,33 \%$ no período após a reforma e aproximadamente $5,48 \%$ a longo prazo. Com uma reforma neutra de arrecadação, o emprego cresce menos no setor intensivo e apresenta queda menos expressiva no setor não intensivo, de modo que, com o setor não intensivo passando a obter crescimento no estoque de capital a curto prazo, o produto desse setor fica estável no segundo estado estacionário da economia. Nesse sentido, as perdas do setor não intensivo acabam sendo atenuadas em detrimento das firmas intensivas em trabalho.

\section{RESULTADOS MACROECONÔMICOS PARA AS FAMÍLIAS}

Considerando a reforma 1, a Figura 7 apresenta os comportamentos obtidos para o consumo. Como se pode observar, ocorrem aumentos de consumo no curto e longo prazos. Nesse sentido, as famílias apresentam trajetórias moderadamente crescentes, impulsionando o consumo relativamente menor no presente para consumir mais no futuro. Em linhas gerais, os grupos 1 a 5 são os mais beneficiadas, com as famílias 3 e 4 (rendimentos entre 1.245 e 4.150 reais) apresentando as maiores taxas de crescimento de consumo a curto e longo prazos. No curto prazo, as taxas de crescimento do consumo variam entre $3,85 \%$ (família 7 ) e $4,1 \%$ (família 3 ) e a longo prazo, os valores ficam entre $4 \%$ (família 7 ) e $4,25 \%$ (família 3). 
Figura 5: Resultados setoriais com trajetórias de transição após reforma 2. No eixo vertical, têm-se as variações percentuais relativas aos valores calibrados no primeiro estado estacionário. 0 eixo horizontal é o tempo em anos após a reforma
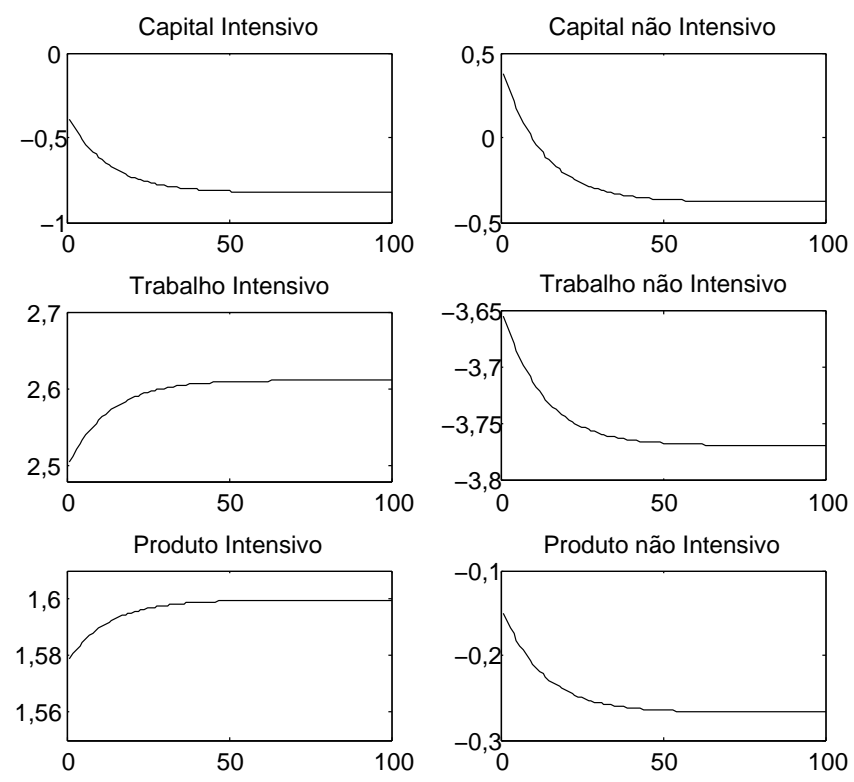

A segunda reforma (ver Figura 8) modifica a trajetória de consumo das famílias, que passam a valorizar mais o consumo de curto prazo. Mesmo assim, ocorrem crescimentos significativos a curto e longo prazos. Como na primeira reforma, as famílias 1 a 5 são as mais beneficiadas, tendo maior destaque para os grupos 3 e 4, que apresentam as maiores taxas de crescimento a curto e longo prazos. Em termos de crescimento do consumo, relativamente à primeira mudança, observam-se taxas de crescimento inferiores, variando aproximadamente entre $3,2 \%$ (família 7 ) e $3,4 \%$ (família 3) no primeiro instante após a reforma e entre $2,9 \%$ (família 7) e $3,1 \%$ (família 3) no segundo equilíbrio estacionário da economia.

A Figura 9 ilustra os resultados dos consumos após a terceira reforma. Em um cenário neutro de arrecadação, as variações nos consumos das famílias comportam-se de maneira bastante semelhante e apresentam valores inferiores aos das reformas 1 e 2 . Os consumos dos sete grupos crescem de forma menos expressiva no curto prazo, chegando a retrair levemente a longo prazo. Esse cenário justifica-se pelo fato de que a elevada tributação sobre o faturamento das firmas intensivas onera o fator capital, deixando as famílias menos promensas à formação de poupança para consumo futuro.

O comportamento das horas de trabalho pode se visto nas Figuras 10, 11 e 12 (reformas 1, 2 e 3, respectivamente). Com a reforma 1 , o preço relativo do consumo aumenta, provocando elevações nas horas de trabalho dos sete grupos familiares, que ofertam mais mão de obra para o setor intensivo, elevando seus níveis de renda. Nesse cenário os grupos familiares preferem impulsionar mais o consumo às horas de trabalho, descrevendo trajetórias de consumo suaves, trabalhando mais no presente (relativamente às horas de trabalho de longo prazo) e consumindo mais no futuro (relativamente ao consumo de curto prazo). Entre os grupos, as famílias 6 e 7 (classes de maior rendimento) impulsionam mais as horas de trabalho, enquanto que as famílias 3 e 4 (classes de rendimento intermediário) seguem no 
Figura 6: Resultados setoriais com trajetórias de transição após reforma 3. No eixo vertical, têm-se as variações percentuais relativas aos valores calibrados no primeiro estado estacionário. 0 eixo horizontal é o tempo em anos após a reforma
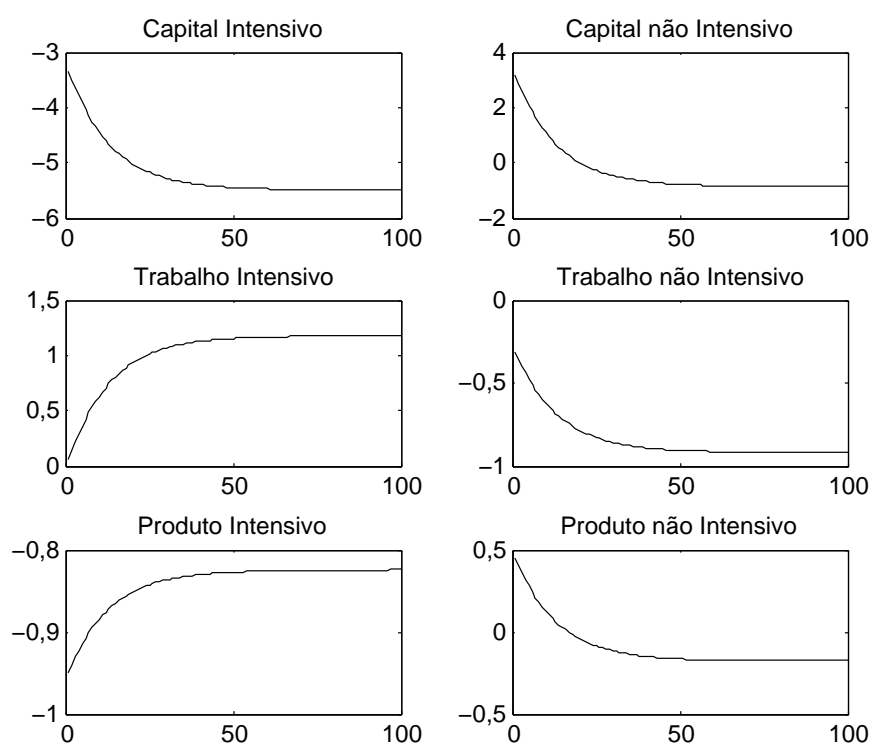

Figura 7: Comportamento do consumo das famílias em relação ao primeiro estado estacionário após a reforma 1. No eixo vertical têm-se as variações percentuais relativas aos valores calibrados no primeiro estado estacionário. $\mathrm{O}$ eixo horizontal é o tempo em anos após a reforma

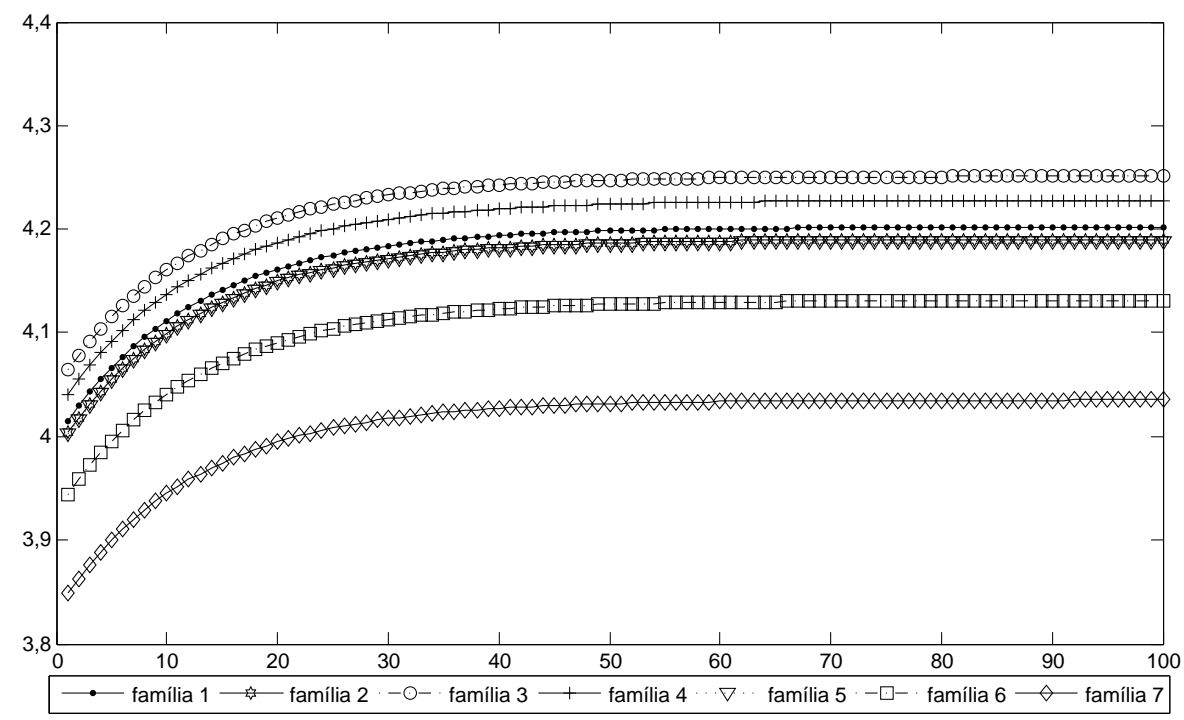


Figura 8: Comportamento do consumo das famílias em relação ao primeiro estado estacionário após a reforma 2 . No eixo vertical, têm-se as variações percentuais relativas aos valores calibrados no primeiro estado estacionário. $\mathrm{O}$ eixo horizontal é o tempo em anos após a reforma

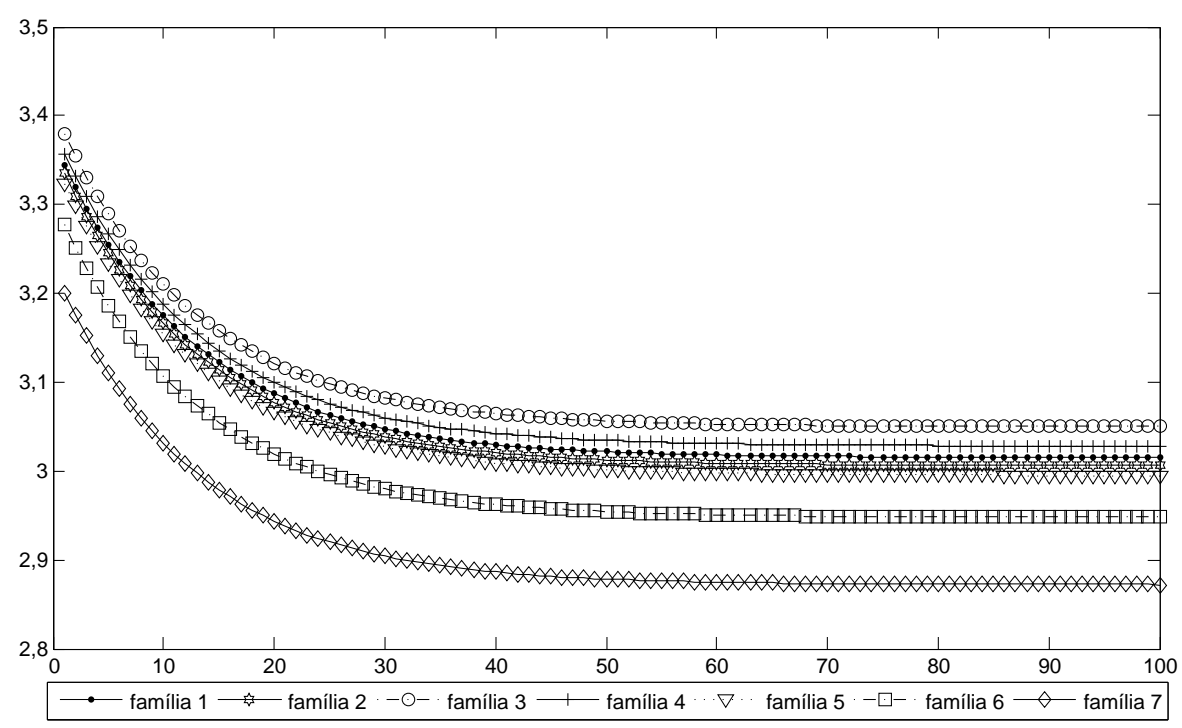

Figura 9: Comportamento do consumo das famílias em relação ao primeiro estado estacionário após a reforma 3. No eixo vertical, têm-se as variações percentuais relativas aos valores calibrados no primeiro estado estacionário. 0 eixo horizontal é o tempo em anos após a reforma

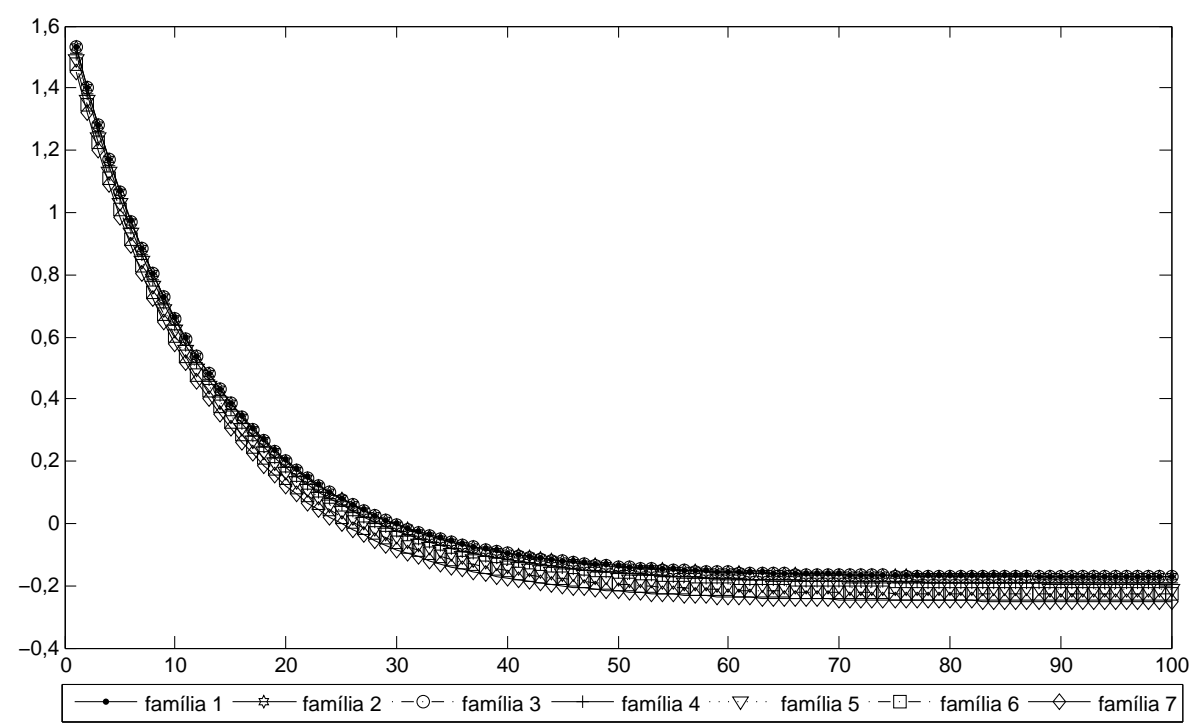


sentido contrário. Os demais grupos apresentam taxas de crescimento das horas de trabalho bastante semelhantes.

Figura 10: Comportamento das horas de trabalho em relação às condições do primeiro estado estacionário e após a reforma 1 . No eixo vertical, têm-se as variações percentuais relativas aos valores calibrados no primeiro estado estacionário. O eixo horizontal é o tempo em anos após a reforma

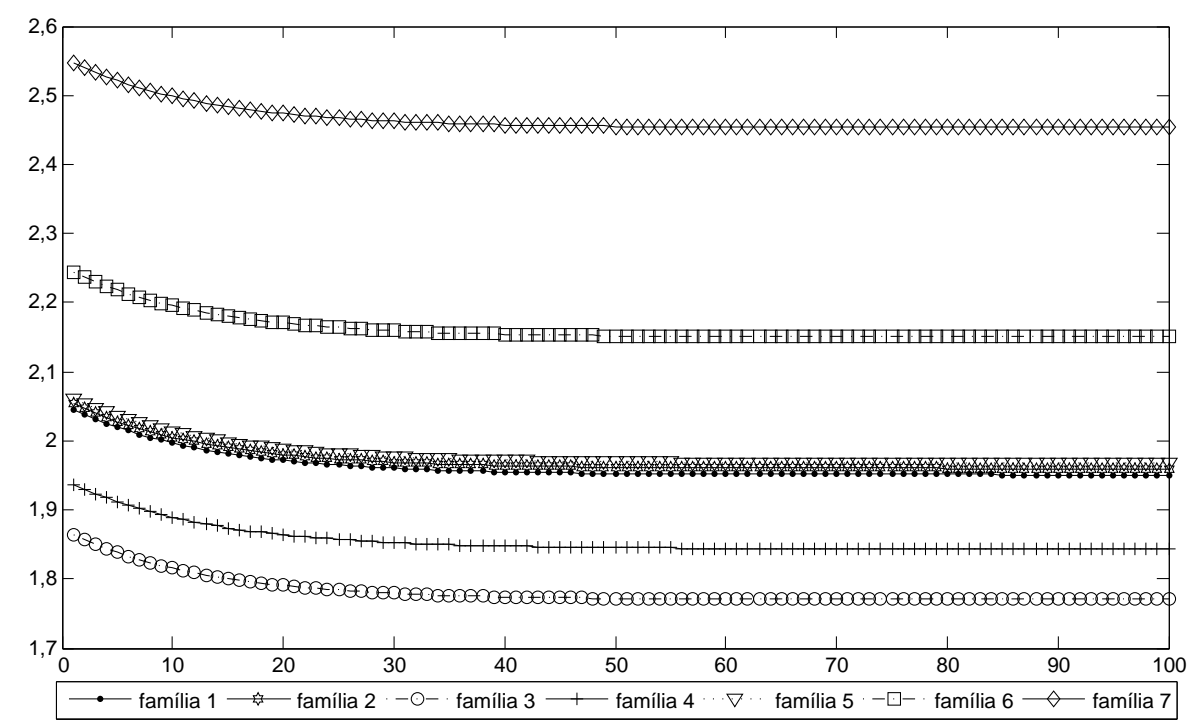

A segunda reforma (ver Figura 11) atenua o crescimento do consumo das famílias, mas ainda mantém o aumento do preço relativo do consumo. Dessa forma, observam-se taxas de crescimento inferiores às alcançadas com a primeira reforma. Relativamente aos valores de longo prazo, as horas de trabalho apresentam taxas de crescimento menores no curto prazo. Entre os sete grupos, as famílias 3 e 4 (faixa de renda intermediária) apresentam as menores taxas de crescimento das horas de trabalho. Por outro lado, as famílias 6 e 7 seguem um comportamento contrário. 
Figura 11: Comportamento das horas de trabalho em relação às condições do primeiro estado estacionário e após a reforma 2 . No eixo vertical, têm-se as variações percentuais relativas aos valores calibrados no primeiro estado estacionário. 0 eixo horizontal é o tempo em anos após a reforma

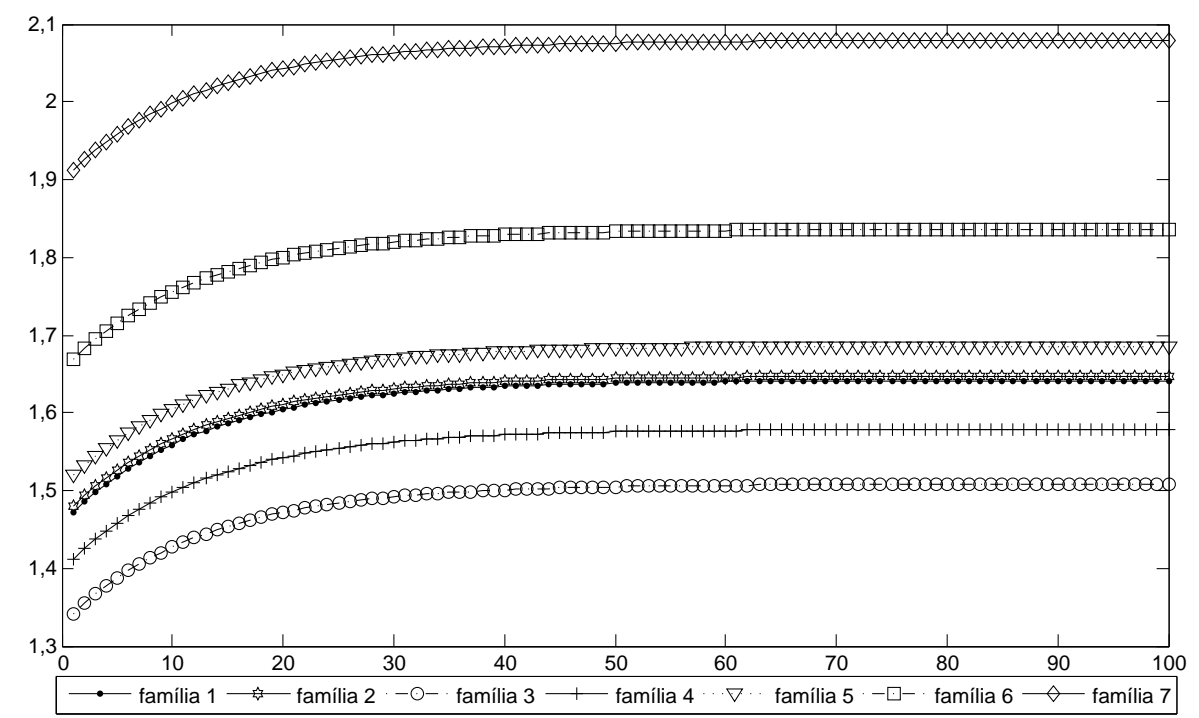


Os resultados associados à terceira reforma podem ser visualizados na Figura 12. No primeiro período após a terceira reforma, as horas de trabalho das famílias 1 a 4 chegam a sofrer leves retrações, que são recuperadas ao longo da transição. Nesse cenário de reforma, as taxas de crescimento do emprego apresentam-se bastante inferiores às obtidas com as duas primeiras mudanças tributárias. Nesse sentido, a maior oneração do fator capital implica baixos crescimentos de consumo e emprego para os grupos familiares.

Figura 12: Comportamento das horas de trabalho em relação às condições do primeiro estado estacionário e após a reforma 3. No eixo vertical, têm-se as variações percentuais relativas aos valores calibrados no primeiro estado estacionário. O eixo horizontal é o tempo em anos após a reforma

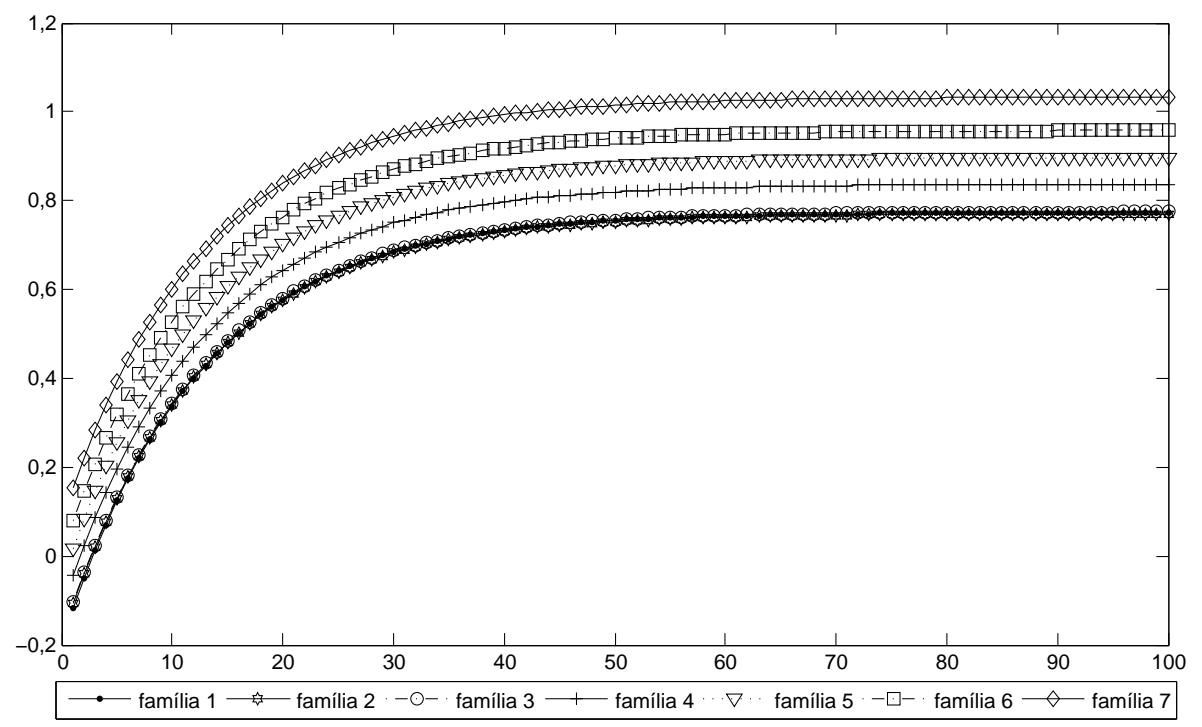

A análise de bem-estar é feita considerando todo o período da transição e seguindo a metodologia utilizada em Paes e Bugarin (2006). Após atualizar os fluxos $\left\{c_{i t} d_{i t}\right\}_{t=1, \ldots, \mathrm{T}}$ e $\left\{y_{i t}\right\}_{t=1, \ldots, \mathrm{T}}$ de cada família $(i=1, \ldots, 7)$, em que $c_{i t}, d_{i t}$ e $y_{i t}=w_{i} h_{i}+r_{i} k_{i}$ denotam, respectivamente, o consumo, a variação compensada de consumo e a renda bruta da $i$-ésima família no $t$-ésimo período da transição. $O$ valor presente da variação de bem-estar da família $i$ é calculado pela expressão

$$
V P w c_{i}=\frac{V P c d_{i}}{V P y_{i}}
$$

em que

$$
V P c d_{i}=\sum_{t=1}^{\mathbf{T}} \frac{c_{i t} d_{i t}}{\prod_{j=0}^{t-1}\left(1+r_{j}\right)}, \quad V P y_{i}=\sum_{t=1}^{\mathbf{T}} \frac{y_{i t}}{\prod_{j=0}^{t-1}\left(1+r_{j}\right)},
$$

sendo $r_{t}$ a taxa de juros do período $t$. O bem-estar agregado é calculado por $w c=\sum_{i=1}^{7} \eta_{i}\left(V P w c_{i}\right)$.

A Tabela 6 contém os valores presentes das variações de bem-estar por família. Como é possível observar, a análise deixa claro que, em todas as reformas, o ganho de bem-estar é superior para as famílias de baixa renda e menor para as famílias com rendimentos mais elevados. Além disso, os ganhos são maiores com a reforma 1 , tanto do ponto de vista agregado como desagregado. A terceira reforma 
praticamente não altera o bem-estar das famílias. Vale destacar que, como todo o período de transição foi considerado, o resuldado para o bem-estar diverge do que foi encontrado em Cavalcanti (2008). Além desse ponto, tem-se o fato do estudo proposto por Cavalcanti (2008) desconsiderar a heterogeneidade das famílias e das firmas, o que torna a presente análise mais realista.

Tabela 6: Bem-estar em valor presente, após cada reforma (bem-estar agregado na última coluna)

\begin{tabular}{|c|c|c|c|c|c|c|c|c|}
\hline Família & 1 & 2 & 3 & 4 & 5 & 6 & 7 & Agregado \\
\hline \multicolumn{9}{|c|}{ Após Reforma 1} \\
\hline $\begin{array}{l}\text { Ganho de } \\
\text { Bem-Estar }\end{array}$ & 2,0300 & 2,0311 & 1,9638 & 1,8151 & 1,6968 & 1,5879 & 1,4596 & 1,9090 \\
\hline \multicolumn{9}{|c|}{ Após Reforma 2} \\
\hline $\begin{array}{l}\text { Ganho de } \\
\text { Bem-Estar }\end{array}$ & 1,6017 & 1,6021 & 1,5423 & 1,4171 & 1,3190 & 1,2300 & 1,1275 & 1,4982 \\
\hline \multicolumn{9}{|c|}{ Após Reforma 3} \\
\hline $\begin{array}{l}\text { Ganho de } \\
\text { Bem-Estar }\end{array}$ & 0,4088 & 0,4078 & 0,3690 & 0,3111 & 0,2698 & 0,2369 & 0,2066 & 0,3552 \\
\hline
\end{tabular}

Figura 13: Comportamento da renda do trabalho relativamente ao primeiro estado estacionário após a reforma 1 . No eixo vertical, têm-se as variações percentuais relativas aos valores calibrados no primeiro estado estacionário. $\mathrm{O}$ eixo horizontal é o tempo em anos após a reforma

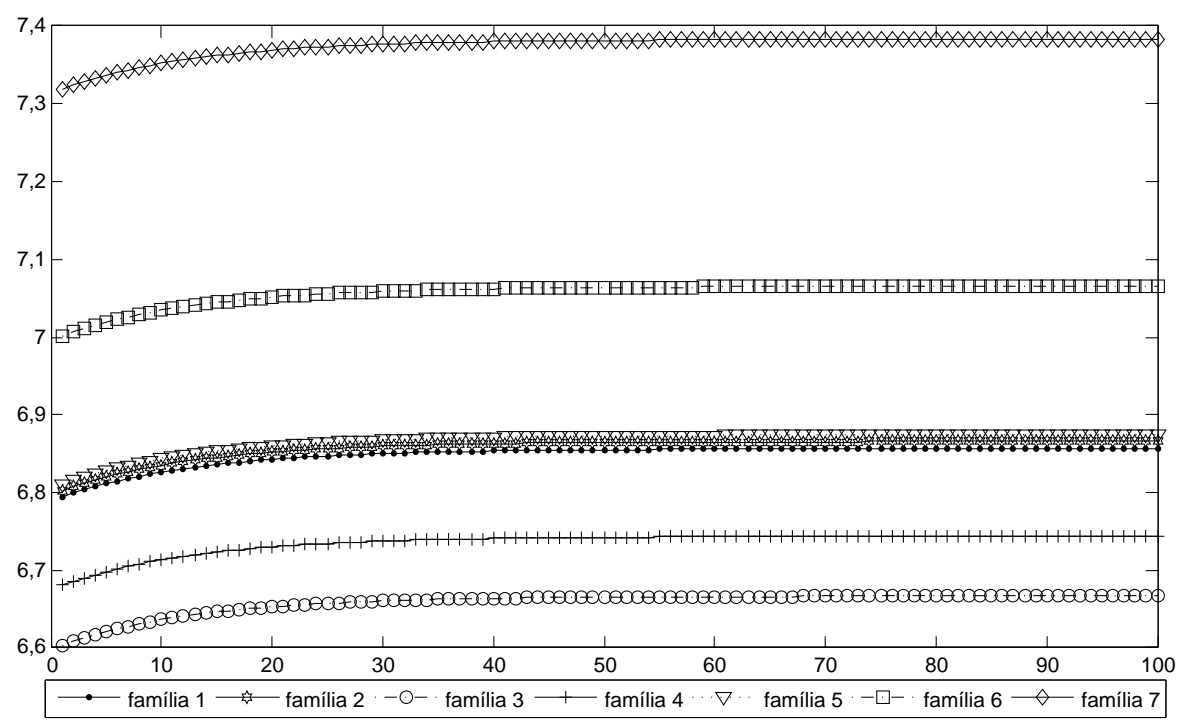

As trajetórias dos rendimentos do trabalho correspondentes à reforma 1 podem ser vistas na Figura 13. Como pode-se observar, os rendimentos do trabalho são reflexos dos comportamentos das horas trabalhadas pelas famílias. De maneira geral, as famílias mais ricas, por apresentarem variações no 
estoque de capital inferiores precisam aumentar mais as horas de trabalho para sustentar o consumo a longo prazo. Essa maior variação nas horas de trabalho implica maior crescimento da renda laboral desses grupos.

Os resultados correspondentes às reformas 2 e 3 são mostrados nas Figuras 14 e 15 . Com é possível perceber, o aumento da alíquota sobre o faturamento das firmas intensivas tende a reduzir o crescimento dos rendimentos do trabalho das familias, este fato é notável no cenário neutro de arrecadação. As variações no estoque de capital das famílias são mostradas nas Figuras 16, 17 e 18 (reformas 1 a 3 , respectivamente). Apenas a primeira reforma afeta positivamente o estoque de capital das famílias, com os grupos de baixa renda apresentando taxas de crescimento levemente superiores aos demais. Com a elevação da alíquota sobre o faturamento das firmas intensivas, as famílias poupam menos e para fazer frente ao consumo, trabalham mais a longo prazo. A terceira reforma onera fortemente o capital das famílias, que chega a retrair cerca de $4 \%$ para os dois grupos de menor rendimento (famílias 1 e 2 ).

Figura 14: Comportamento da renda do trabalho relativamente ao primeiro estado estacionário após a reforma 2. No eixo vertical, têm-se as variações percentuais relativas aos valores calibrados no primeiro estado estacionário. $\mathrm{O}$ eixo horizontal é o tempo em anos após a reforma

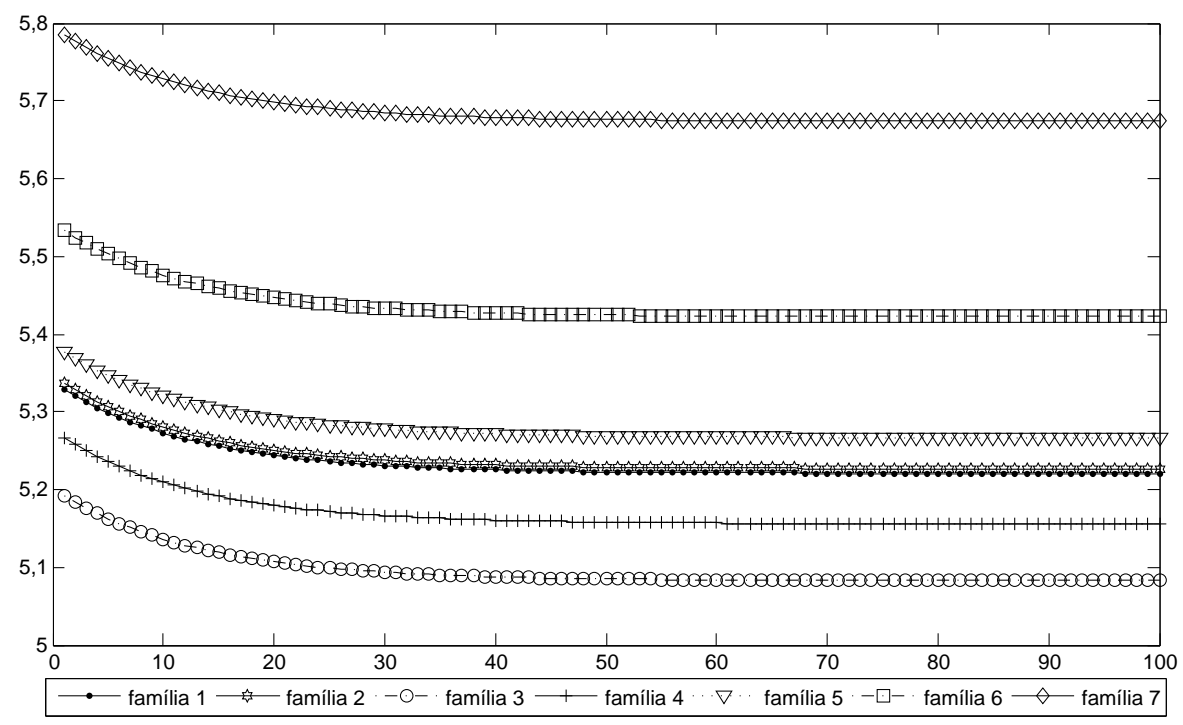

De forma geral, os ganhos de bem-estar quando a reforma é neutra em relação a arrecadação são bastante modestos, o que sugere que esta reforma não é capaz de diminuir as distorções do atual sistema tributário. Os ganhos de eficiência das reformas 1 e 2 decorrem quase que exclusivamente da redução da carga tributária. O que a reforma 3 permite vislumbrar é que a mudança da base tributária da folha de pagamentos para o faturamento não é capaz de atenuar as graves distorções presentes no sistema tributário brasileiro.

\subsection{Análise de progressividade e distribuição de renda}

Na presente seção as três reformas tributárias são analisadas sob a ótica de progressividade e distribuição de renda. A situação inicial corresponde a economia brasileira em 2009 caracterizada pela 
Figura 15: Comportamento da renda do trabalho relativamente ao primeiro estado estacionário após a reforma 3. No eixo vertical, têm-se as variações percentuais relativas aos valores calibrados no primeiro estado estacionário. 0 eixo horizontal é o tempo em anos após a reforma

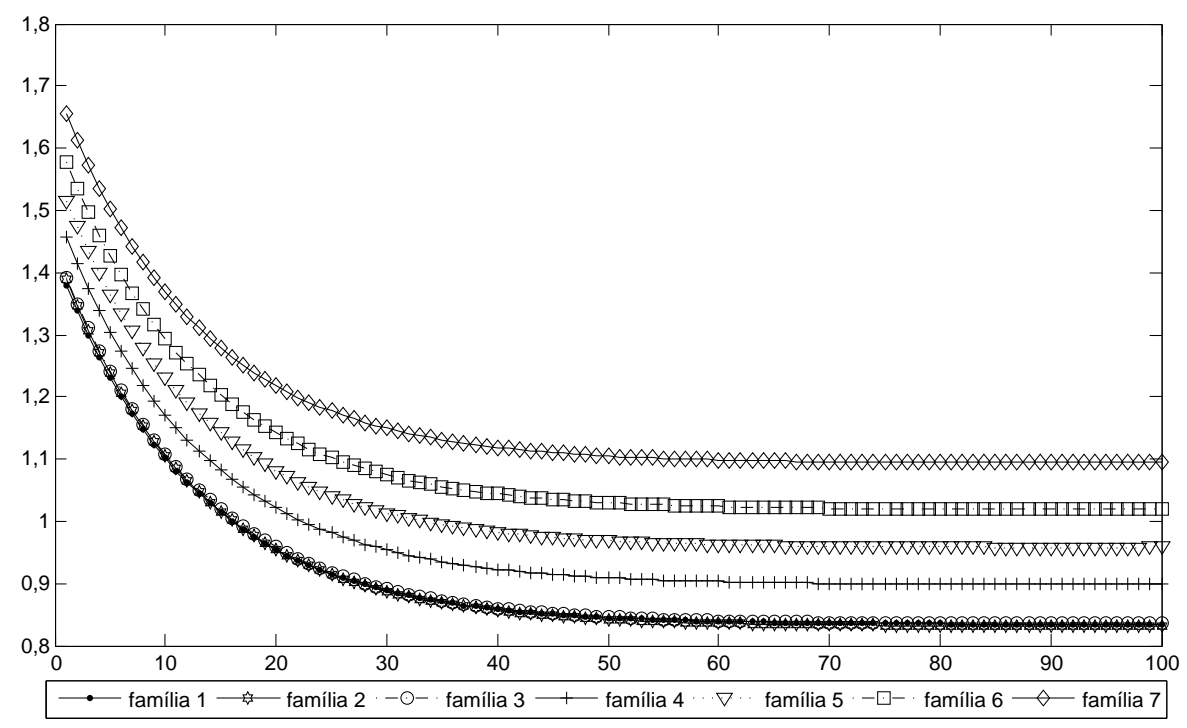

Figura 16: Comportamento do estoque de capital relativamente ao primeiro estado estacionário após a reforma 1 . No eixo vertical, têm-se as variações percentuais relativas aos valores calibrados no primeiro estado estacionário. 0 eixo horizontal é o tempo em anos após a reforma

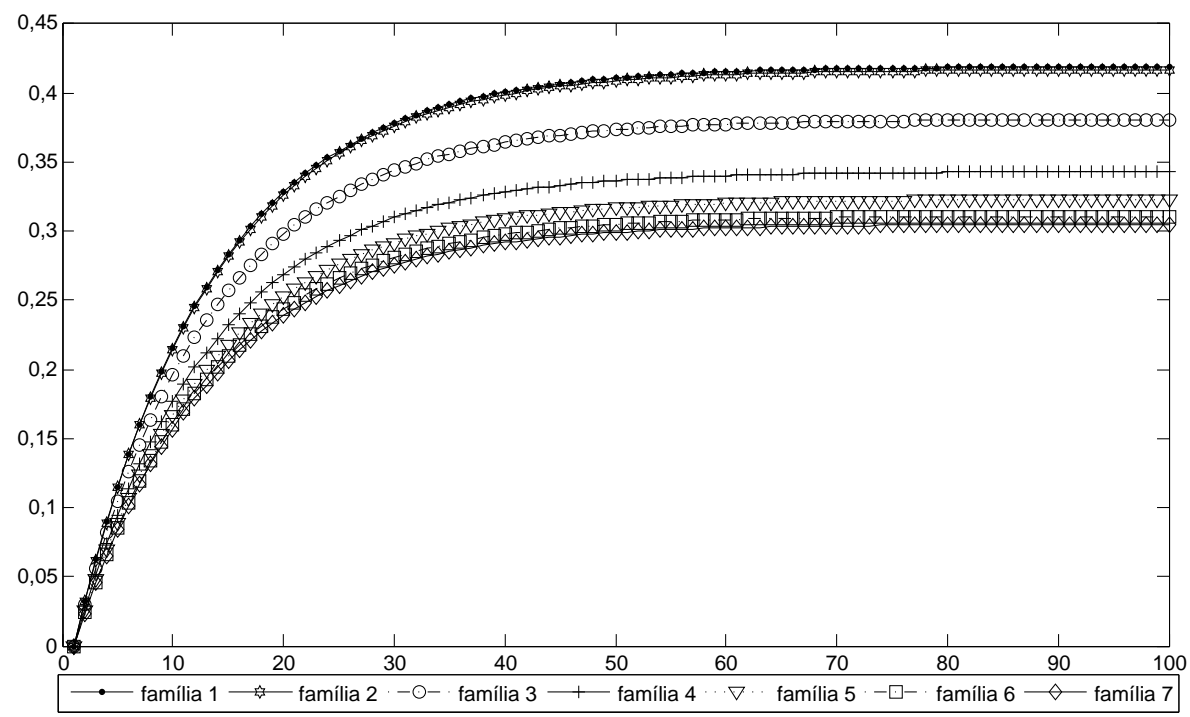


Figura 17: Comportamento do estoque de capital relativamente ao primeiro estado estacionário após a reforma 2. No eixo vertical, têm-se as variações percentuais relativas aos valores calibrados no primeiro estado estacionário. 0 eixo horizontal é o tempo em anos após a reforma

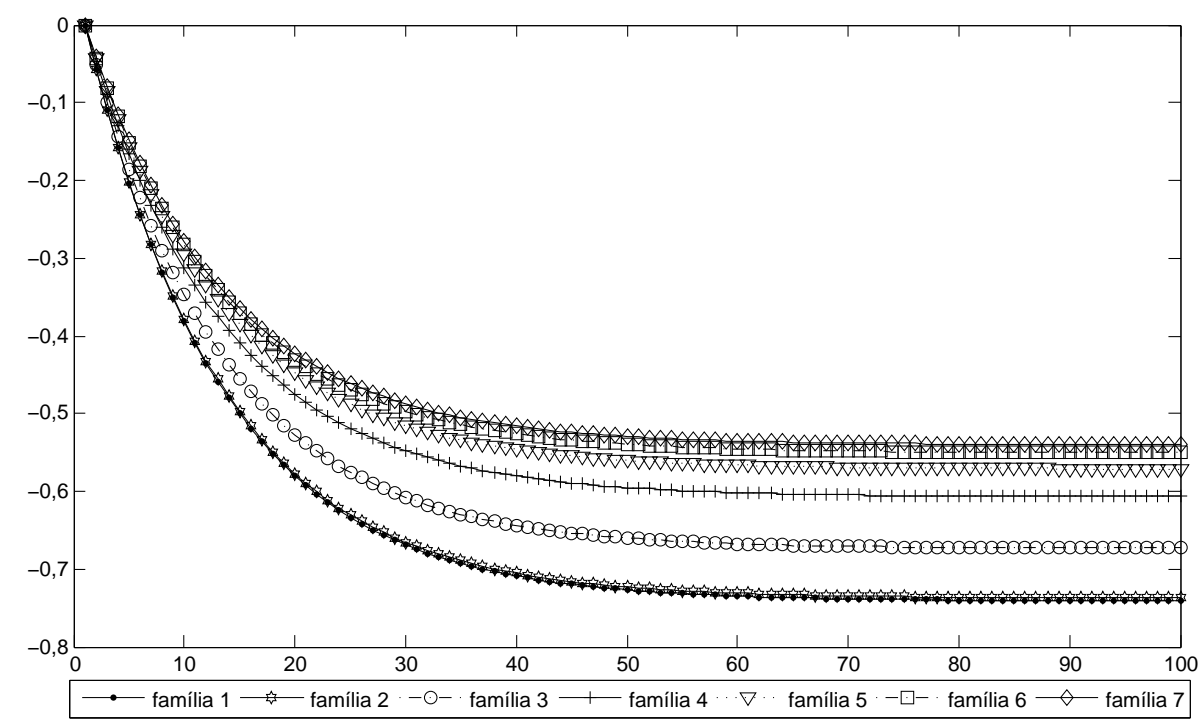

Figura 18: Comportamento do estoque de capital relativamente ao primeiro estado estacionário após a reforma 3. No eixo vertical, têm-se as variações percentuais relativas aos valores calibrados no primeiro estado estacionário. 0 eixo horizontal é o tempo em anos após a reforma

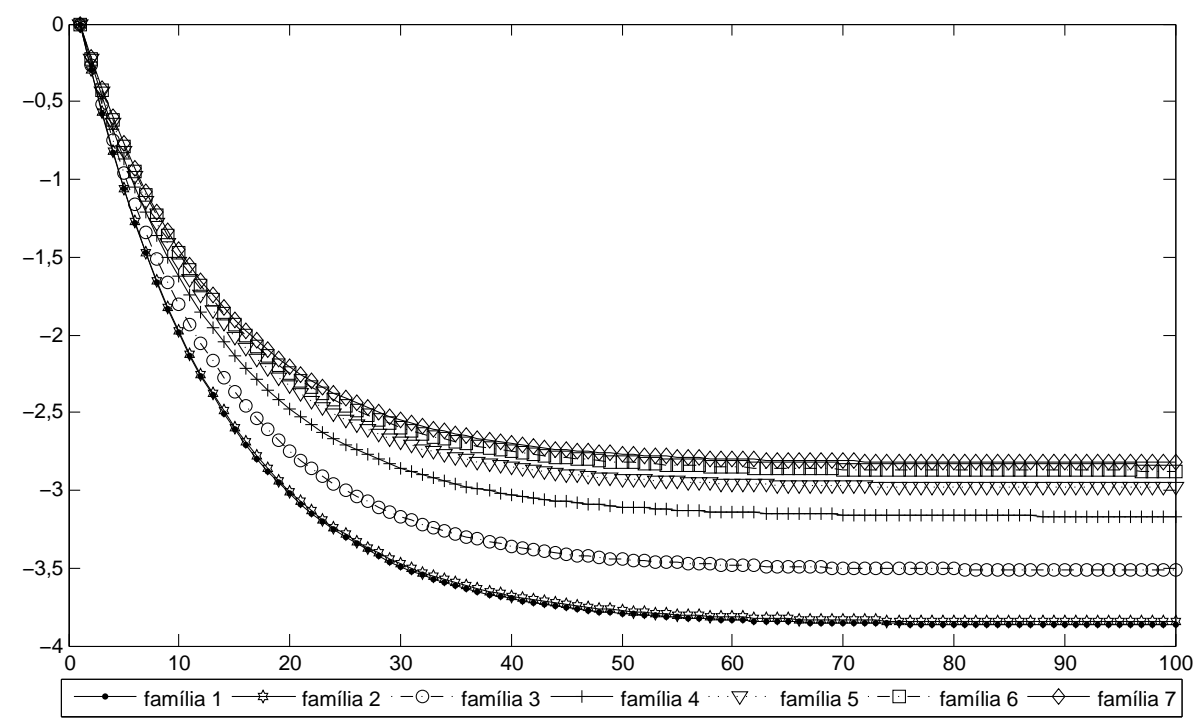


distribuição da POF 2008/2009 adotada neste trabalho. Como fator resultante, deseja-se captar o impacto distributivo das mudanças tributárias propostas sobre esta economia.

A avaliação da distribuição da renda é feita considerando o total em impostos pago pelas famílias. $\mathrm{Na}$ análise, as transferências do governo são consideradas na composição da renda líquida de cada grupo. Dessa forma, o rendimento líquido do $i$-ésimo grupo familiar $\left(R L F_{i t}\right)$ é dado pela expressão $R L F_{i t}=R B T_{i t}+T_{i}-D T_{i t}, i=1, \ldots, 7$, sendo $T_{i}, R B T_{i t}$ e $D T_{i t}$, respectivamente, a transferência do governo, a renda bruta e a despesa total em impostos associados à $i$-ésima família.

As trajetórias do índice de Gini Gini (1912) para cada um dos cenários de reforma tributária pode ser observada na parte superior da Tabela 7. Como é possível verificar, considerando os rendimentos brutos (antes dos impostos), nenhuma das reformas afeta substancialmente o índice de Gini. O mesmo ocorre em relação aos rendimentos líquidos, i.e., as reformas não impactam a distribuição de renda de forma relevante.

A análise de progressividade também considera os totais em impostos pagos pelos grupos familiares. Para tanto, são calculados o índices de Kakwani Kakwani (1977) e de Reynolds-Smolenski Reynolds e Smolensky (1977). Na parte inferior da Tabela 7 é possível observar a evolução dos índices de Kakwani (lado esquerdo) e de Reynolds-Smolenski (lado direito), todos calculados para cada um dos cenários de reforma. Pelo que se pode constatar, as três reformas aumentam o indicador de Kakwani, refletindo um impacto levemente positivo sobre a progressividade do sistema tributário. Este impacto positivo é bastante reduzido quando se considera a reforma 3, i.e., com o cenário neutro da arrecadação.

$\mathrm{O}$ índice de Reynolds-Smolenski indica o quanto cada reforma contribui para o aumento ou redução na desigualdade de renda. Na Tabela 7 percebe-se que as reformas 1 e 2 aumentaram o indicador de Reynolds-Smolenski, sinalizando que as duas propostas fazem com que se reduza o impacto concentrador de renda da tributação. O sistema tributário brasileiro continuaria concentrando renda, mas em menor escala com as reformas 1 e 2. Já a reforma 3 diminui o indicador de Reynolds-Smolenski, ou seja, acentua o efeito concentrador do sistema tributário. Este resultado não é surpresa para uma mudança neutra da arrecadação, que concentra ainda mais a tributação sobre os impostos indiretos, que tendem a ser fortemente regressivos.

Tabela 7: Trajetórias dos índices de Gini, Kakwani e Reynolds-Smolenski para cada um dos cenários de reforma

\begin{tabular}{|c|c|c|c|c|c|c|}
\hline \multicolumn{7}{|c|}{ Índice de Gini } \\
\hline \multicolumn{4}{|c|}{ Renda Bruta } & \multicolumn{3}{|c|}{ Renda Líquida } \\
\hline Período & Reforma 1 & Reforma 2 & Reforma 3 & Reforma 1 & Reforma 2 & Reforma 3 \\
\hline 0 & 0,5177533 & 0,5177533 & 0,5177533 & 0,5010693 & 0,5010693 & 0,5010693 \\
\hline 1 & 0,5168488 & 0,5169625 & 0,5172803 & 0,5003533 & 0,5003938 & 0,5005057 \\
\hline 2 & 0,5168447 & 0,5169697 & 0,5173183 & 0,5003503 & 0,5003992 & 0,5005338 \\
\hline 100 & 0,5167962 & 0,5170565 & 0,5177865 & 0,5003139 & 0,5004640 & 0,5008795 \\
\hline \multicolumn{4}{|c|}{ Índice de Kakwani } & \multicolumn{3}{|c|}{ Índice de Reynolds-Smolenski } \\
\hline Período & Reforma 1 & Reforma 2 & Reforma 3 & Reforma 1 & Reforma 2 & Reforma 3 \\
\hline 0 & 0,0049927 & 0,0049927 & 0,0049927 & $-0,016684$ & $-0,016684$ & $-0,016684$ \\
\hline 100 & 0,0060398 & 0,0058203 & 0,0052044 & $-0,016482$ & $-0,016592$ & $-0,016907$ \\
\hline
\end{tabular}




\section{CONCLUSÃO}

No presente trabalho, em um estudo para o Brasil, foram analisados impactos econômicos de mudanças tributárias baseadas na substituição da alíquota previdenciária patronal por uma alíquota de $1 \%$ (reforma 1) ou $2 \%$ (reforma 2) sobre o faturamento de firmas intensivas em trabalho. Além disso, a fim de avaliar o impacto das reformas sob intervenção do governo, uma análise neutra em relação à arrecadação do governo foi realizada. Nesse cenário, a alíquota tributária é de $4,7 \%$ sobre o faturamento intensivo. Observando os resultados para os agregados da economia, nas reformas 1 e 2, foram observados aumentos no consumo, produto e principalmente no emprego. No entanto, com a terceira reforma, os resultados são pouco significativos, o consumo mantém-se estável, o produto retrai levemente e o emprego aumenta levemente. O efeito sobre o estoque de capital depende da magnitude da alíquota sobre o faturamento adotada, tornando-se menos expressivo à medida em que o valor da alíquota aumenta.

No lado setorial, as firmas não intensivas em trabalho reduzem levemente o estoque de capital e o produto, apresentando forte retração na demanda por emprego após as reformas 1 e 2 . Por outro lado, as firmas intensivas em trabalho apresentam um comportamento crescente na demanda laboral, mas que desacelera na medida em que a alíquota sobre o faturamento do setor aumenta. No cenário neutro de arrecadação (reforma 3) os resultados setoriais mostram-se pouco expressivos.

No lado das famílias, o consumo cresce de forma mais intensa após a primeira reforma, diminuindo as taxas de crescimento com o aumento da alíquota incidente sobre o faturamento das firmas intensivas. Nesse sentido, apenas a primeira reforma implicou em trajetórias crescentes com taxa moderada de crescimento para o consumo, induzindo as famílias a pouparem mais no presente para aumentar o consumo futuro. As horas de trabalho crescem de forma mais expressiva após a primeira reforma. Em relação aos ganhos de bem-estar, em todos os cenários analisados, o bem-estar é maior entre os grupos familiares pobres e são pouco expressivos para a terceira mudança. Verificou-se, portanto, que os resultados são modestos em um cenário de arrecadação neutra, deixando as famílias com taxas de crescimento bem próximas para o consumo, horas de trabalho e estoque de capital.

De maneira geral, os resultados obtidos pelo cenário neutro de arrecadação revelam que os impactos positivos das reformas 1 e 2 decorrem basicamente da redução da carga tributária. Seria mais adequado buscar reformas que não apenas sejam capazes de reduzir a elevada carga tributária, mas que também permitam ganhos de eficiência.

\section{BIBLIOGRAFIA}

Altig, D., Auerbach, A. J., Kotlikoff, L. J., Smetters, K. A., \& Walliser, J. (2001). Simulating fundamental tax reform in the United States. American Economic Review, pages 574-595.

Auerbach, A. J. \& Kotlikoff, L. J. (1987). Dynamic Fiscal Policy, volume 11. Cambridge University Press Cambridge.

Bitencourt, M. B. \& Teixeira, E. C. (2009). Impactos dos encargos sociais na economia brasileira. Nova Economia, 18(1):53-86.

Broyden, C. G. (1965). A class of methods for solving nonlinear simultaneous equations. Mathematics of Computation, 19(92):577-593.

Cavalcanti, T. V. (2008). Tributos sobre a folha ou sobre o faturamento? Efeitos quantitativos para o Brasil. Revista Brasileira de Economia, 62(3):249-261.

Christiano, L. J., Eichenbaum, M., \& Evans, C. L. (2005). Nominal rigidities and the dynamic effects of a shock to monetary policy. Journal of political Economy, 113(1):1-45. 
Cooley, T. F. \& Hansen, G. D. (1992). Tax distortions in a neoclassical monetary economy. Journal of Economic Theory, 58(2):290-316.

Ferreira, P. C. G. \& Araújo, C. H. V. (1999). Reforma tributária, efeitos alocativos e impactos de bem-estar. Revista Brasileira de Economia, 53(2):133-166.

Fullerton, D. (1982). On the possibility of an inverse relationship between tax rates and government revenues. Journal of Public Economics, 19(1):3-22.

Gini, C. (1912). Variabilità e mutabilità: Contributo allo studio delle distribuzioni e delle relazioni statistiche, Studi Economico-Giuridici della Facoltà di Giurisprudenza della Regia Università di Cagliari. Cuppini, Bologna, 3(2).

Kakwani, N. C. (1977). Measurement of tax progressivity: An international comparison. The Economic Journal, 87(345):71-80.

Lucas, R. E. (1990). Supply-side economics: An analytical review. Oxford Economic Papers, 42(2):293-316.

Paes, N. L. (2011). Reforma tributária: Os efeitos macroeconômicos e setoriais da PEc 233/2008. Estudos Econômicos (São Paulo), 41(2):487-512.

Paes, N. L. (2012). Os impactos da alteração da contribuição previdenciária patronal para a indústria. Estudos Econômicos (São Paulo), 42(4):773-799.

Paes, N. L. \& Bugarin, M. N. S. (2006). Reforma tributária: Impactos distributivos, sobre o bem-estar e a progressividade. Revista Brasileira de Economia, 60(1):33-56.

Prescott, E. C. (2002). Prosperity and depression. The American Economic Review, 92(2):1-15.

Reynolds, M. O. \& Smolensky, E. (1977). Public expenditures, taxes, and the distribution of income: The United States, 1950, 1961, 1970. Academic Press New York. 